University of Louisville

ThinkIR: The University of Louisville's Institutional Repository

8-2015

\title{
Mapping debris-covered glaciers in the Cordillera Blanca, Peru : an object-based image analysis approach.
}

\author{
Donald J. Biddle \\ University of Louisville
}

Follow this and additional works at: https://ir.library.louisville.edu/etd

Part of the Geography Commons

\section{Recommended Citation}

Biddle, Donald J., "Mapping debris-covered glaciers in the Cordillera Blanca, Peru : an object-based image analysis approach." (2015). Electronic Theses and Dissertations. Paper 2220.

https://doi.org/10.18297/etd/2220

This Master's Thesis is brought to you for free and open access by ThinkIR: The University of Louisville's Institutional Repository. It has been accepted for inclusion in Electronic Theses and Dissertations by an authorized administrator of ThinkIR: The University of Louisville's Institutional Repository. This title appears here courtesy of the author, who has retained all other copyrights. For more information, please contact thinkir@louisville.edu. 
MAPPING DEBRIS-COVERED GLACIERS IN THE CORDILLERA BLANCA, PERU: AN OBJECT-BASED IMAGE ANALYSIS APPROACH

\title{
By
}

Donald J. Biddle

B.S., University of Louisville, 2005

\author{
A Thesis \\ Submitted to the Faculty of the \\ College of Arts and Sciences of the University of Louisville \\ in Partial Fulfillment of the Requirements \\ for the Degree of \\ Master of Science \\ in Applied Geography \\ Department of Geography and Geosciences \\ University of Louisville \\ Louisville, Kentucky
}

August 2015 
Copyright 2015 by Donald J. Biddle

All rights reserved 

MAPPING DEBRIS-COVERED GLACIERS IN THE CORDILLERA BLANCA, PERU: AN OBJECT-BASED IMAGE ANALYSIS APPROACH

\author{
By \\ Donald J. Biddle \\ B.S., University of Louisville, 2005
}

A Thesis Approved on

August 3, 2015

By the following Thesis Committee:

Thesis Advisor

Keith R. Mountain

Andrea E. Gaughan

Michael A. Croasdaile 


\section{ACKNOWLEDGEMENTS}

There are so many people without whose guidance and support this thesis would not have come to fruition. To thank them all by name would be major work in its own right! If I must pare the list for this limited space it should begin with my advisors, Dr. Keith Mountain and Dr. Andrea Gaughan. They challenged me to be the best version of myself, even - nay - especially when it was not the easiest way forward. Thank you also to Dr. Michael Croasdaile for putting his geographer's hat back on to see me through this process, and providing an invaluable outside perspective. A very special thank you to Dr. Carol Hanchette, for her patient encouragement over the (many) years it has taken to reach this point. She reminded me that yes, I can do this. Thanks to Forrest Stevens for the crash course in R coding and machine learning that led to a major breakthrough that helped push me over the hump with this project. My brain still hurts. To my lovely wife Nicole, thank you for putting up with me through the deepest moments of frustration, and being a constant companion, confidante, and comedy sidekick...not just now, but always. And finally, thank you to my parents Ron and Candy Biddle, for always trusting in my ability to me find my own way, and being there with open arms to set me back on track when I hit a dead end. 


\begin{abstract}
MAPPING DEBRIS-COVERED GLACIERS IN THE CORDILLERA BLANCA, PERU: AN OBJECT-BASED IMAGE ANALYSIS APPROACH

Donald J. Biddle
\end{abstract}

July 27, 2015

Accurate remote-sensing based inventories of glacial ice are often hindered by the presence of supraglacial debris cover. Attempts at automated mapping of debris-covered glacier areas from remotely-sensed multispectral data have met with limited success due to the spectral similarity of supraglacial debris to nearby bedrock, moraines, and fluvial deposition features. Data-fusion approaches leveraging terrain and/or thermal data with multispectral data have yielded improved results in certain geographic regions, but remain unproven in others. This research builds on the data-fusion approaches from the literature and explores the efficacy of object-based image analysis (OBIA) and tree-based machine learning classifiers using Landsat OLI imagery and SRTM elevation data, in effort to map debris-covered glaciers in the Cordillera Blanca range of Peru. Results suggest that the OBIA and machine learning methods render advantages over traditional methods given the unique morphological settings associated with debris-covered glaciers. Accurate inventories of glacial mass and debris-covered glaciers in the Cordillera Blanca are important for understanding the unique water resource, natural hazards, and climate change implications associated with these tropical mountain glaciers. 


\section{TABLE OF CONTENTS}

PAGE

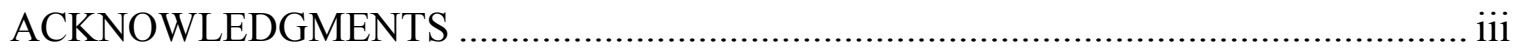

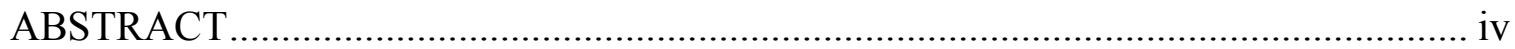

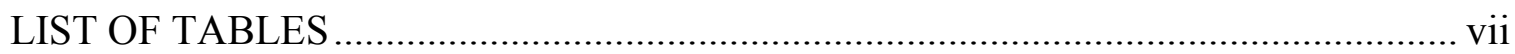

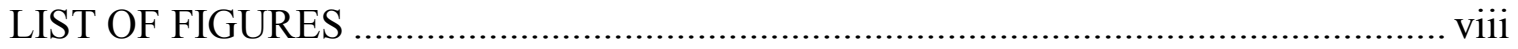

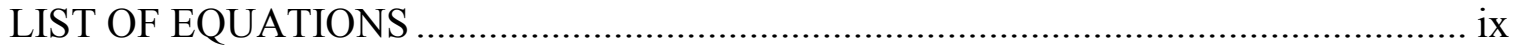

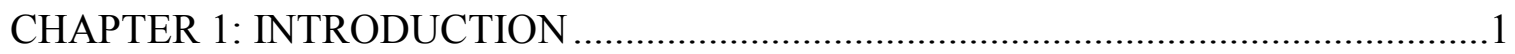

Research Objectives and Hypotheses ...................................................................

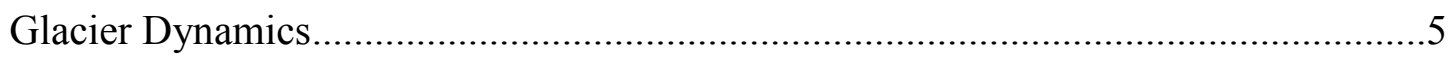

Characterizing Glacial Environments and Change Dynamics .......................................8

Remote Sensing of Debris-Covered Glaciers ............................................................14

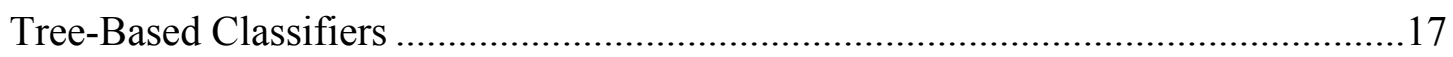

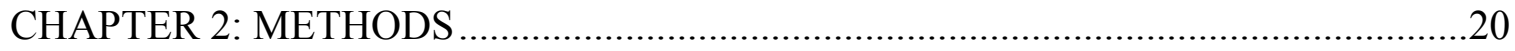

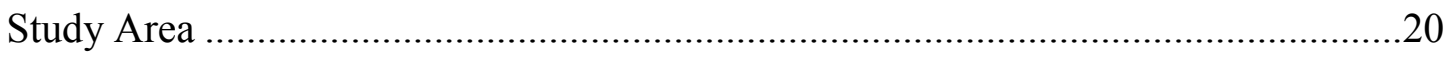

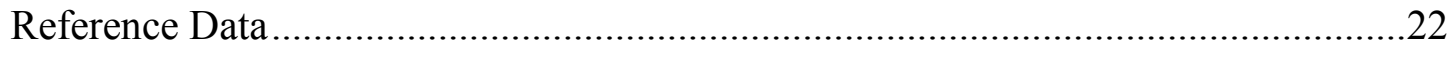

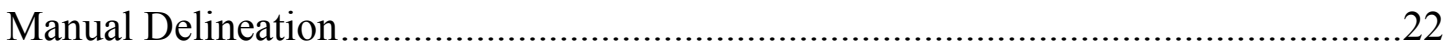

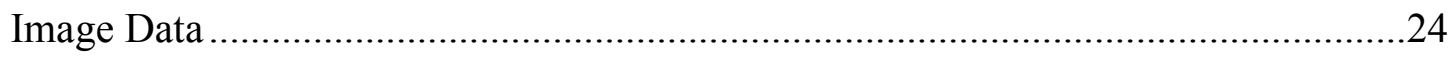

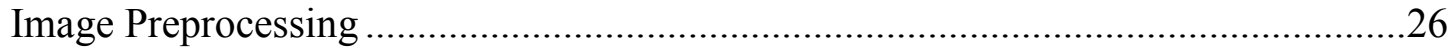

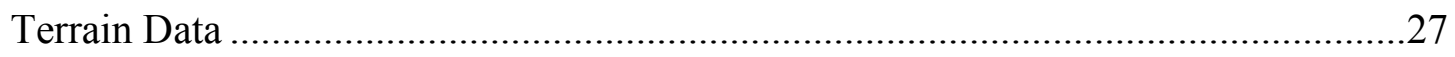

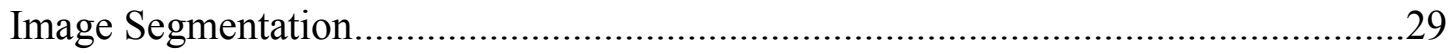

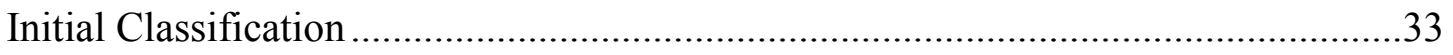


Tree-Based Classifiers

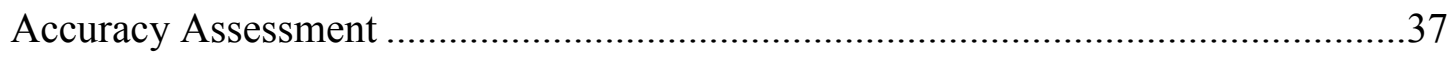

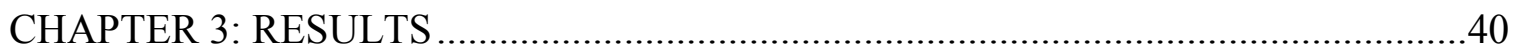

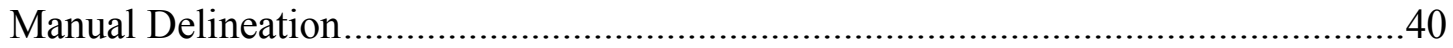

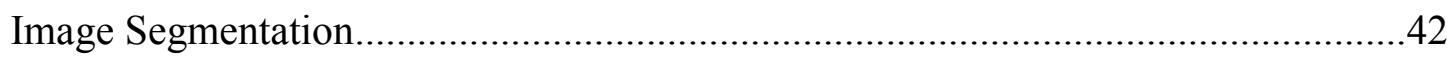

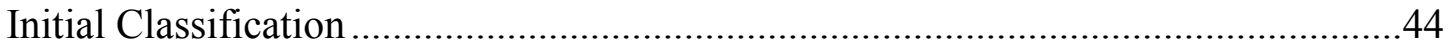

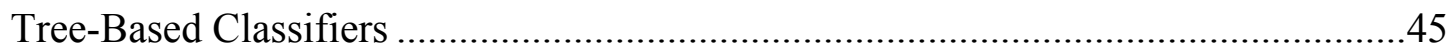

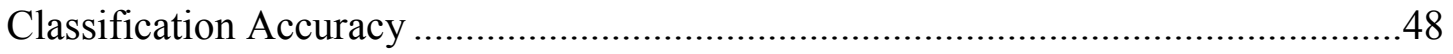

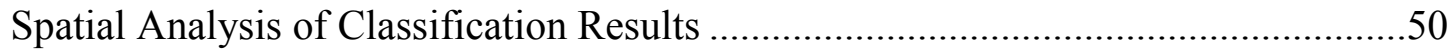

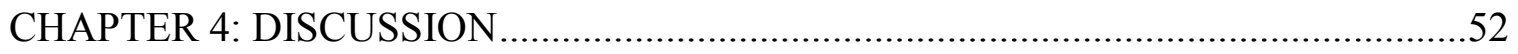

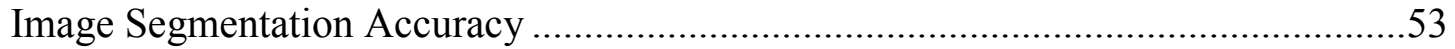

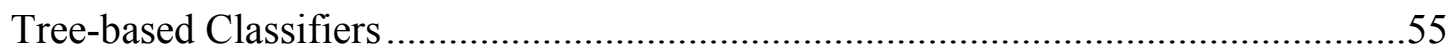

Characteristics of DCGs in the Cordillera Blanca ...............................................60

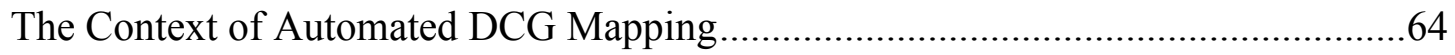

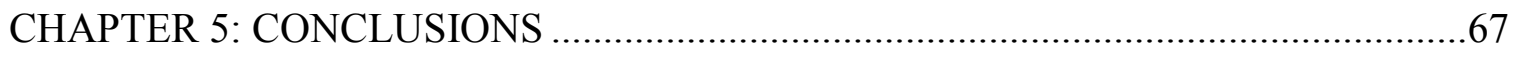

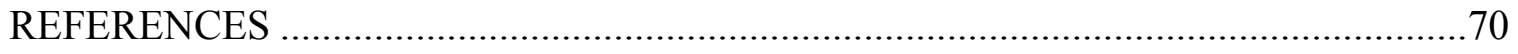

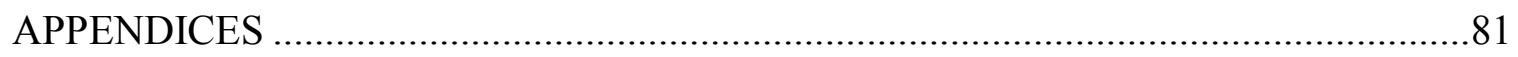

Appendix A: R programming code for tree-based classifiers .................................81

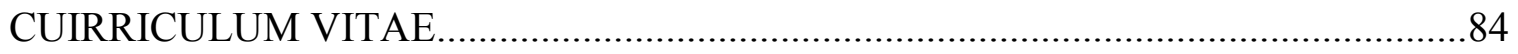




\section{LIST OF TABLES}

TABLE

PAGE

1.1 Spectral bands and their applications for remote sensing of glaciers. ....................12

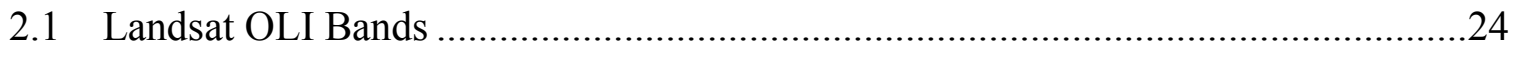

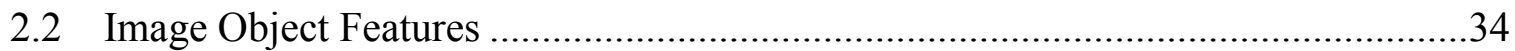

3.1 Results of manual delineation of DCGs vs. GLIMS database ..............................40

3.2 Statistics from repeat digitization of three select DCGs ...................................41

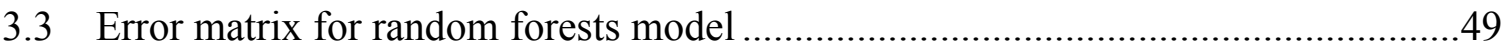

3.4 Error matrix for conditional inference tree model ...........................................49 


\section{LIST OF FIGURES}

FIGURE PAGE

1.1 Chacraraju debris-covered glacier tongue ..................................................

1.2 Spectral reflectance curves for snow and ice ............................................... 11

2.1 Study area

2.2 Landsat OLI true color composite image of Cordillera Blanca range .....................26

2.3 Segmentation demonstrating effects of scale parameter..................................... 31

2.4 Segmentation demonstrating effect of shape parameter ....................................32

2.5 Segmentation demonstrating effects of compactness parameter ............................33

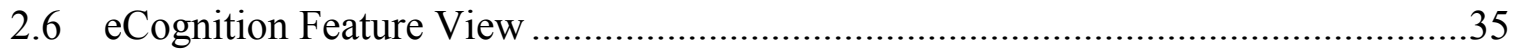

3.1 Debris-covered glacier boundaries from repeat manual delineations .....................41

3.2 True color composite of study area showing final segmentation results ................43

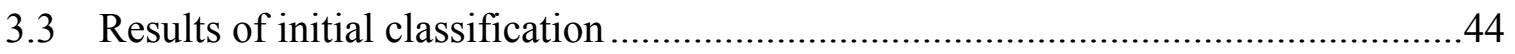

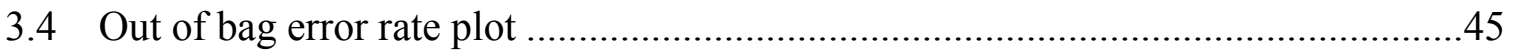

3.5 Variable importance plot for random forest model..........................................46

3.6 Tree diagram for conditional inference tree................................................47

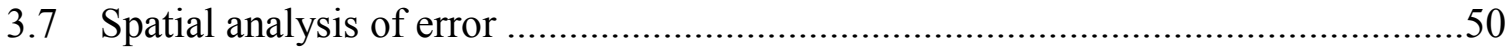

4.1 Potential debris-covered glaciers identified by random forests classification..........58 


\section{LIST OF EQUATIONS}

$\begin{array}{ll}\text { FIGURE } & \text { PAGE }\end{array}$

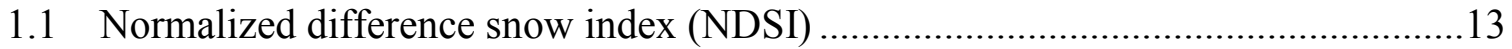

1.2 Normalized difference vegetation index (NDVI) ........................................... 13

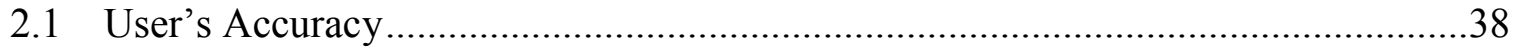

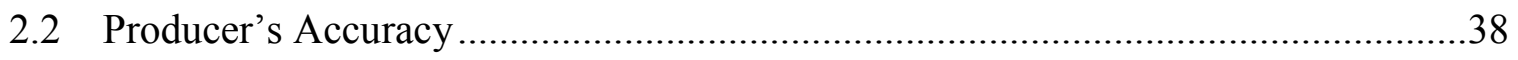

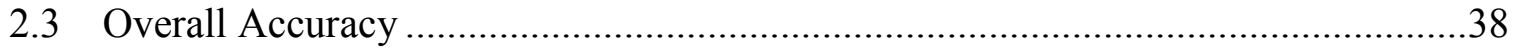

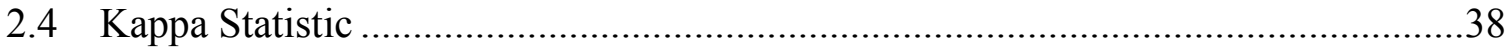

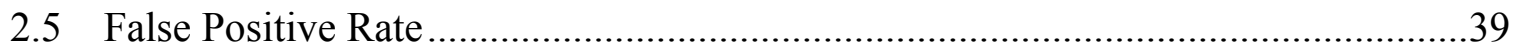




\section{CHAPTER 1: INTRODUCTION}

Glacial systems have long occupied a central role in discussions of climate change, as the equilibrium state of glaciers is a direct result of the global climate system (Benn and Evans 2010). Since the "Little Ice Age" (16 ${ }^{\text {th }}$ to mid-19 $9^{\text {th }}$ centuries $)$ the fluctuations of glacier ice has served as a conspicuous indicator of climate change, an inextricable link between the nebulous, often contradictory realm of climate science and the real, tangible evidence of changes on the landscape. In quantitative terms, ice core data extracted from alpine glaciers and ice caps have provided the foundation of our understanding of Earth's climate history and given context to the rate and magnitude of contemporary climate change (Dansgaard et al. 1993, Thompson et al. 1995, Petit et al. 1999).

Debris-covered glaciers (DCGs) represent a vital, if sometimes overlooked component of glacial systems in mountain environments. The presence of supraglacial debris cover on the tongues of mountain glaciers can affect melt rates, alternately increasing rates of ablation in cases of thin debris cover or diminishing ablation under thick debris cover (Brock et al. 2010). Debris cover also obscures the true extents of glacial ice, making for difficulties in accurate inventorying of glacier areas and their respective fluctuations in response to climate change and other factors (Ghosh, Pandey

and Nathawat 2014, Shukla, Gupta and Arora 2010, Veettil 2012, Paul, Huggel and Kääb 2004). In regions where local populations are entirely dependent on glacial meltwaters for water supplies, accurate assessment of glacial hydrology is vital to planning for 
sustainable use of water resources (Mark and Seltzer 2003, Baraer et al. 2012).

Furthermore, changes in glacial environments in mountain regions, specifically with regard to DCGs, can exacerbate the potential for geohazards like mass movements and glacial lake outburst flooding (Benn et al. 2012, Reynolds 2000).

Since in-situ monitoring of high mountain glaciers is difficult and expensive due to the inaccessible and rugged nature of the terrain, remote sensing and geographic information science (GIS) techniques are commonly employed in effort to characterize land cover in glacial environments (Pellikka and Rees 2009, Paul et al. 2002b, Bishop et al. 2004, Raup et al. 2007, Huggel et al. 2002). Satellite image data from moderateresolution sensors like Landsat have been successfully used to map the extents of clean glacial ice and to quantify their changes over time (Raup et al. 2007, Sidjak 1999). However, accurate remote-sensing based inventories of glacial ice are often hindered by the presence of supraglacial debris cover. Attempts at automated mapping of DCGs from remotely-sensed multispectral data have met with limited success due to the spectral similarity of supraglacial debris to nearby bedrock, moraines, and fluvial deposition features (Racoviteanu, Williams and Barry 2008, Racoviteanu et al. 2008, Burns and Nolin 2014). Data-fusion approaches that leverage terrain and/or thermal data alongside multispectral data have yielded improved results in certain geographic regions, but remain unproven in others (Shukla, Gupta and Arora 2010, Bolch et al. 2007).

In recent years, object-based image analysis (OBIA) has emerged as an alternative framework for analyzing image data from multiple sources (Dupuy, Lainé and Tormos 2012, Saliola 2014, Berger et al. 2013). While pixel-based image analysis methods employ spectral information on a pixel-by-pixel basis, OBIA segments images into 
collections of "image objects" - groups of pixels that share similar spectral characteristics. OBIA classification techniques can then leverage a wealth of information about image objects unaccounted for by pixel-based methods, including morphometric variables, textural features, and contextual relationships between neighboring image objects. This expanded breadth of information may then be incorporated into classification algorithms to in order to improve accuracy and efficacy.

This thesis explores the value of OBIA in conjunction with two types of tree-based machine learning classifiers in the development of an automated method extraction of DCGs using multisource image data. The research is centered on the assumption that DCGs are unique morphological entities, a class of objects that may share a common signature that could permit their extraction from image data given an appropriate selection of spectral and terrain information. The study area for this work is the Cordillera Blanca mountain range of Peru (approx. $9^{\circ} 10^{\prime} \mathrm{S}, 77^{\circ} 30^{\prime} \mathrm{W}$ ). The Cordillera Blanca holds the largest concentration of tropical mountain glaciers of any place on Earth (Kaser and Osmaston 2002). Tropical glaciers occupy a unique position in the discussion of global climate change as they are sensitive indicators of change exhibiting more immediate response to climatic variation than mid-latitude and polar glaciers (Wagnon et al. 1999, Kaser and Osmaston 2002, IPCC 2013). The Cordillera Blanca also holds a large number of DCGs of varying size and character. While DCGs in other regions may display a more distinct and consistent character in terms of length, slope, elevation, etc., the DCGs of the Cordillera Blanca exhibit great variability. This makes the region a suitable, if more challenging arena for the development of an automated technique for extraction of DCG extents from remotely sensed image data. 


\section{Research Objectives and Hypotheses}

The objectives of the present research include the following:

1.) Evaluate the capacity of object-based image analysis, and specifically multiresolution image segmentation of pan-sharpened Landsat Operational Land Imager (OLI) Visible and Near Infrared and Shuttle Radar Topography Mission (SRTM) terrain data, to identify the boundaries of debris-covered glaciers in the Cordillera Blanca range as discrete morphometric units distinct from their surroundings. Hypothesis 1: Multiresolution image segmentation will be successful in identifying the boundaries of debris-covered glaciers in the Cordillera Blanca range.

2.) Evaluate the efficacy of tree-based classifiers, including conditional inference trees and random forests, in the classification of image objects as "debris-covered glacier" or "other" in the Cordillera Blanca range. Hypothesis 2: Tree-based classifiers will achieve classification accuracies for debris-covered glaciers which are consistent with the target accuracy of $85 \%$ recommended for land cover classification by the United States Geological Survey (Anderson 1976). Random forests will yield higher classification accuracies than conditional inference trees.

3.) Through objectives 1 and 2 , explore the most important predictor variables and their associated critical values in discriminating debris-covered glaciers in the Cordillera Blanca region of Peru. Hypothesis 3: Debris-covered glaciers will exhibit a unique signature in terms of slope, temperature, and texture that is distinct from the signature of surrounding bedrock and moraine deposits. Variable importance metrics 
associated with tree-based classifiers will be capable of identifying critical values for these variables and others.

The paucity of literature regarding object-based image analysis and tree-based classifiers with respect to mapping of debris-covered glaciers suggests that the findings of this study may have important implications for the field of remote sensing in glacial environments. Additionally, the few efforts at semi-automated or automated mapping of debris-covered glaciers in the Cordillera Blanca have been unsuccessful (Burns and Nolin 2014). Given the documented challenge of mapping debris-covered glaciers in the Cordillera Blanca, any success here would hold promise for future efforts. The techniques developed here could also be useful in other areas with large concentrations of debriscovered glaciers. Results of this research would be appropriate for publication in the following selected journals: Remote Sensing of Environment, International Journal of Remote Sensing, Annals of Glaciology, Journal of Glaciology, and Cold Regions Science and Technology.

\section{Glacier Dynamics}

Glaciers represent nearly $10 \%$ of land cover globally, and up to $75 \%$ of Earth's freshwater stores, covering 15 million square kilometers of Earth's surface (NSIDC 2015a). Glaciers form and advance when annual snowfall exceeds snowmelt, that is, when accumulation exceeds ablation. Each year, the weight of new snow causes compression of the underlying layers remaining from previous seasons. Over decades, centuries, and millennia, this compression and associated increase in density transforms 
snow into firn (granular snow), and firn into glacier ice (Benn and Evans 2010). Glaciers are found where the local climate regime permits this accumulation over time, mainly at high latitudes and high altitudes, with large winter snowfalls and mild summer temperatures. In regions with extreme topographic relief, cirque glaciers form in accumulation basins flanked by steep ridges. Flowing out of these cirque glaciers into downstream valleys are valley glaciers. The pattern of valley glaciers on the landscape resembles in many cases that of a drainage basin and river system. When local climate shifts toward higher precipitation and colder temperatures, and accumulation exceeds ablation, these glaciers advance down-valley to lower altitudes, snaking through the valley floor like rivers of ice. Conversely, when precipitation patterns shift towards drier and/or warmer conditions, ice melt increases and valley glaciers retreat. In the late $20^{\text {th }}$ and early $21^{\text {st }}$ centuries $\mathrm{CE}$, increases in global temperatures have driven the retreat of valley glaciers worldwide (Vaughan et al. 2013). A number of distinct landforms are associated with this retreat, including terminal and medial moraines, proglacial and supraglacial lakes, and debris-covered glaciers (Stokes et al. 2007, Tweed and Carrivick 2015, Benn et al. 2012).

Supraglacial debris often cover portions of the ablation zones of valley glaciers in areas of extreme topographic relief (Kirkbride 2011). Indeed, a majority of valley glaciers in environments such as the Himalaya, Karakoram, Alaska, and the Cordillera Blanca are debris-covered glaciers. Rockfall, rock avalanche, and other mass movements from surrounding terrain result in the deposition of large angular material on glacier surfaces, while aeolian and fluvial processes may contribute smaller, rounded sediments (Hambrey 
1994, Kirkbride 2011). Basal debris, forced from the bottom of the glacier to the surface, may also be present in cases where glacial ice is compressed (Hambrey 1994).

Debris-covered glaciers (e.g. Figure 1.1) play a significant role in the mass-balance of glaciers due to the effects of debris cover on melt rates of underlying ice. A debris cover thinner than the "critical thickness" (where melt rates are equal to that of clean ice) values of $0.01 \mathrm{~m}-0.04 \mathrm{~m}$, lead to increased ice melt resulting from greater absorption of insolation due to the lower albedo of debris. However, with a majority of debris-covered glaciers debris exceeds this critical thickness, leading to an insulating effect due to the low thermal conductivity of the debris material (Brock et al. 2010, Racoviteanu and Williams 2012). The net effect of this insulation and reduced ice melt is that glaciers with significant debris cover have accumulation-area ratios lower than those without (Benn et al. 2003, Nakawo and Rana 1999). Simply put, this means that to preserve equilibrium mass-balance, a debris-covered glacier requires a smaller accumulation area than a similar "clean" glacier.

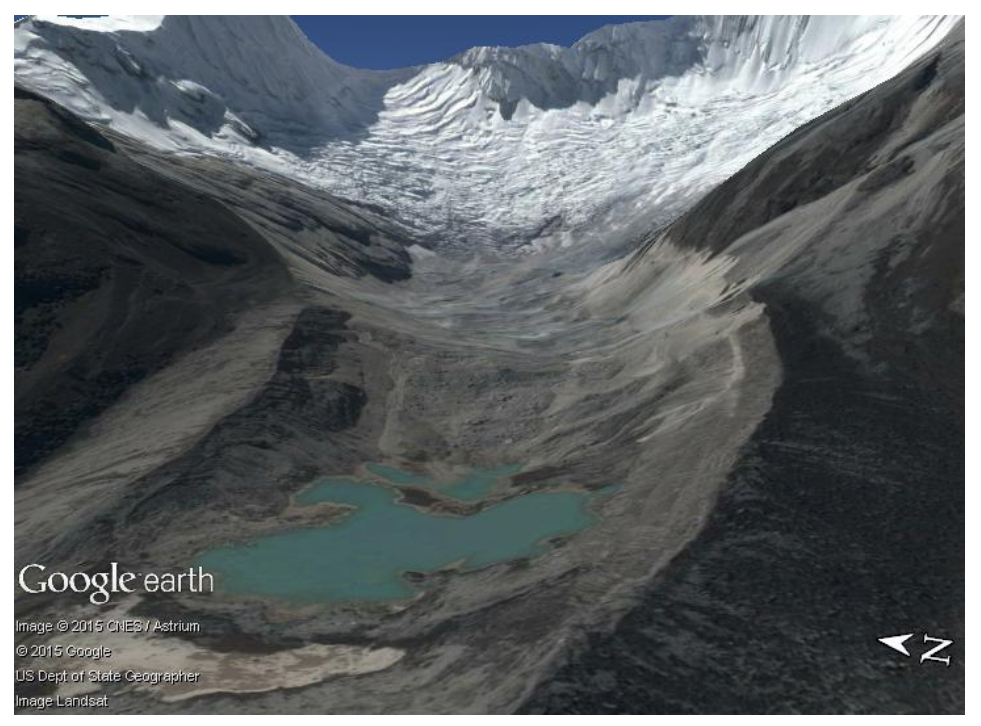

Figure 1.1 Chacraraju debris-covered glacier tongue, Cordillera Blanca range, Peru. Google Earth ${ }^{\mathrm{TM}}$ perspective view. Image: 6/20/2015. 
In addition to their effects on the hydrology of glacial systems, debris-covered glaciers and the dynamics of their change have consequences for human populations. As debris-covered glaciers retreat due to climate change, they represent a threat to downvalley populations by producing potentially dangerous supraglacial and moraine-dammed lakes, and associated glacial lake outburst floods (GLOFs) (Quincey et al. 2005). In the Cordillera Blanca region, the memory of the 1941 Palcacocha GLOF that killed 5,000 people and leveled much of the city of Huaraz still influences public consciousness and government policy where glacial lakes are concerned (Carey 2010). While perhaps less acute than catastrophic outburst flooding, the diminishing of water supplies for drinking water, industry, and hydroelectric power generation by glacier retreat is also a long-term concern for local populations in the Cordillera Blanca region (Mark and Seltzer 2003).

\section{Characterizing Glacial Environments and Change Dynamics}

The necessity to understand the dynamics of change in glacial environments has given rise to a number of metrics to characterize the conditions of glaciers, their health, and the direction and magnitude of change over time. The concept of "mass balance" represents the most fundamental of these metrics. Mass balance refers to the change in a glacier's mass over a given period of time, usually expressed on a seasonal or annual basis. Mass balance is the net result of accumulation and ablation for the time period in question. Mass balance can be measured for individual locations on a glacier, but is more commonly measured for the total area of the glacier - the mean specific mass balance (Benn and Evans 2010). Mass balance can be either positive for advancing glaciers, or negative for retreating glaciers. The most reliable methods for quantifying mass balance 
utilize extensive field measurements of glacier accumulation and ablation, directly recording snow accumulation or melt in relation to stakes fixed in the glacier's surface. This work is most often slow, labor and resource intensive, and in many cases dangerous. Despite these challenges, prolific efforts to collect and record mass balance data for glaciers worldwide have spurred the World Glacier Monitoring Service (WGMS), which details mass balance observations for over 200 glaciers since 1975 (Zemp, Hoelzle and Haeberli 2009). The WGMS has recorded twenty four consecutive years of negative mean cumulative mass balance for the glaciers it monitors (WGMS 2015).

Given the logistical difficulties of field studies, and the need for greater temporal resolution and spatial coverage of glacier monitoring, optical remote sensing techniques have gained favor for quantifying glaciers (Racoviteanu, Williams and Barry 2008, Pellikka and Rees 2009, Raup et al. 2007). While remotely sensed data are clearly not capable of making direct measurements of accumulation and ablation, there are a wealth of proxy data that can be extracted from multispectral image data that allow for close approximation of mass balance without the need for in-situ observation. Glacier area/extent, terminus position, snow cover, and surface temperature are but a few of the myriad properties available through optical remote sensing. With digital elevation model (DEM) data to supplement the analysis additional properties become distinguishable, such as minimum/maximum elevations, average elevations, slope and curvature, etc.

The usefulness of remote sensing techniques in accurately discriminating glaciers and glacier properties rests on the unique spectral response of snow and ice. In general, the high albedo of snow and ice correspond to relatively high reflectance values in the visible (VIS) spectrum $(0.4 \mu \mathrm{m}-0.75 \mu \mathrm{m})$, in contrast to relatively low values in the near 
infrared (NIR, $0.78 \mu \mathrm{m}-0.90 \mu \mathrm{m})$, and very low values in the shortwave infrared (SWIR, $1.5 \mu \mathrm{m}-1.8 \mu \mathrm{m}$ ) (Warren 1982, König, Winther and Isaksson 2001). As fresh snow ages and transitions to firn (granular snow) and eventually glacial ice, its overall reflectivity decreases, while contrasts between reflectance in specific wavelength regions are generally preserved, as seen in Figure 1.1. The introduction of impurities such as fine sediment and dust can also diminish the reflectance of snow and ice. The variation in reflectance of snow versus firn and glacial ice and the spectral resolution of many modern multispectral satellite sensors makes possible the differentiation of bare ice and snow zones (facies) within a glacier (Pellikka and Rees 2009). For imagery acquired at the end of the ablation season (summer or local dry season), the snowline - the interface of the bare ice and snow facies - is often used as an analog for the equilibrium line of the glacier. The equilibrium line is an isoline where net balance is neither positive nor negative (Benn and Evans 2010). The altitude of the equilibrium line (ELA), which can be extracted from DEM data, is used as a measure of the health and change of a glacier. During periods of positive mass balance ELAs may advance to lower elevations, while retreating upslope during negative mass balance phases (Benn and Evans 2010). Remote sensing based observations of changes in ELAs evidence the retreat of glaciers worldwide (Racoviteanu et al. 2008, Loibl, Lehmkuhl and Grießinger 2014). 


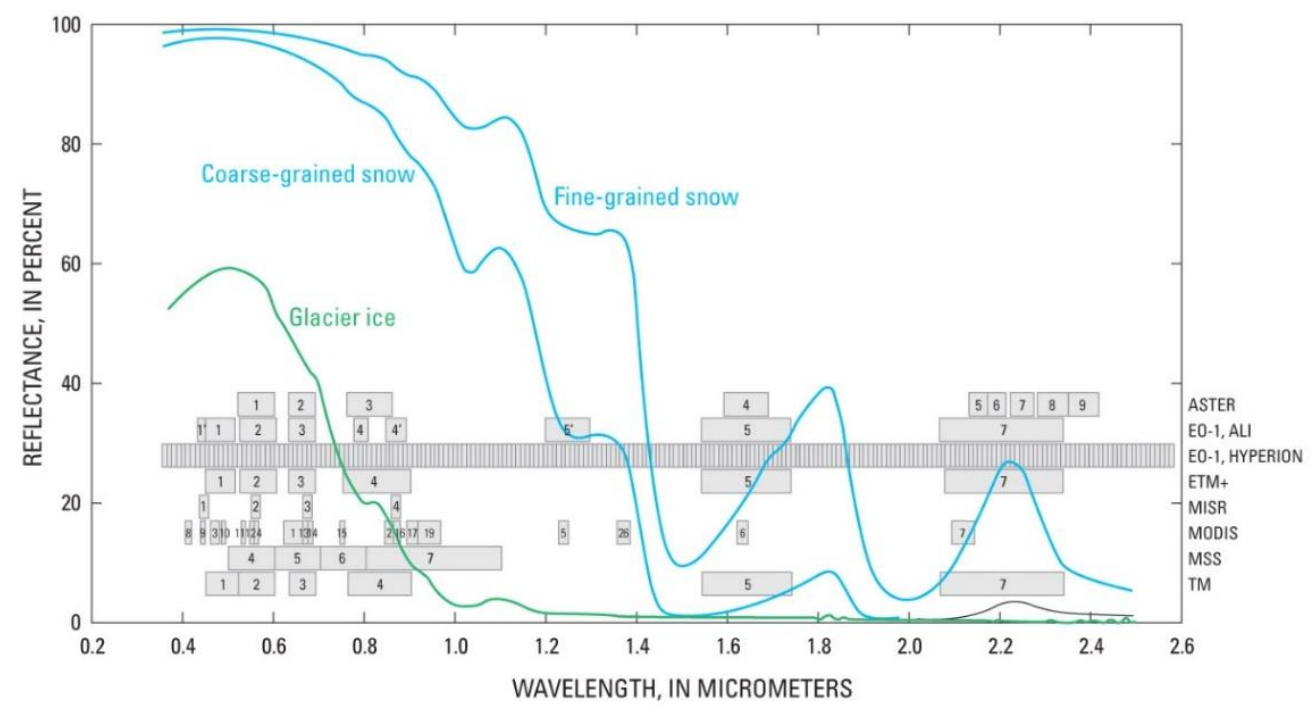

Figure 1.2 Spectral reflectance curves for snow and ice. Bandwidths of common sensors shown for reference. Landsat OLI most closely resembles the "ETM+" sensor in the VNIR and SWIR regions. Image from Williams and Ferrigno (2012).

By accurately mapping glacier extents and modeling the equilibrium line altitude, the glacier's accumulation area ratio (AAR) may be calculated. Above the equilibrium line lies the accumulation zone (roughly equivalent to the snow zone in imagery), and below, the ablation zone (corresponding to the bare ice zone in imagery). The AAR refers to the ratio of the area of accumulation zone to the total area of the glacier (Benn and Evans 2010). For instance, for a glacier with $40 \%$ of its area falling above the equilibrium line, the AAR is 0.4. For tropical glaciers like those found in the Cordillera Blanca, AARs are typically quite high $(\sim 0.8)$ (Kaser and Osmaston 2002). However, the presence of debriscover can cause much lower AARs, as ice melt rates are typically lower under layers of supraglacial debris (Nakawo and Rana 1999).

The simplest and most common application of optical remote sensing in glacial environments is the mapping of glaciers extents. While manual delineation via heads-up digitizing is commonly used with single band imagery, multispectral data offer the ability 
to perform automated classification of glacier extents by exploiting the absorption features of snow and ice in the SWIR region. Table 1.1 depicts the spectral bands commonly employed in mapping of glaciers, and their applications. Because much of the previous work done utilizes Landsat Thematic Mapper (TM) data and refers to spectral products in terms of TM bands, these bands and the corresponding Landsat Operational Land Imager/Thermal Infrared Sensor (hereafter referred to as Landsat OLI) bands are both listed.

Table 1.1 Spectral bands and their applications for remote sensing of glaciers. Adapted from Pellikka and Rees (2009).

\begin{tabular}{|c|c|c|c|c|}
\hline $\begin{array}{c}\text { Wavelengths } \\
(\boldsymbol{\mu m})\end{array}$ & $\begin{array}{c}\text { Common } \\
\text { Name }\end{array}$ & $\begin{array}{c}\text { TM } \\
\text { Band }\end{array}$ & $\begin{array}{c}\text { OLI } \\
\text { Band }\end{array}$ & Application \\
\hline $\mathbf{0 . 4 5}-\mathbf{0 . 5 1}$ & Blue & 1 & 2 & Snow/ice discrim. in shadow, mapping glacier lakes \\
\hline $\mathbf{0 . 5 3}-\mathbf{0 . 5 9}$ & Green & 2 & 3 & Part of NDSI, snow/ice discrim. in shadow \\
\hline $\mathbf{0 . 6 4}-\mathbf{0 . 6 7}$ & Red & 3 & 4 & Part of NDVI, useful in some band ratios \\
\hline $\mathbf{0 . 8 5}-\mathbf{0 . 8 8}$ & NIR & 4 & 5 & Part of NDVI, useful in some band ratios \\
\hline $\mathbf{1 . 5 7}-\mathbf{1 . 6 5}$ & SWIR & 5 & 6 & Key band for auto classification (ratio, NDSI) \\
\hline $\mathbf{2 . 1 1}-\mathbf{2 . 2 9}$ & SWIR & 7 & 7 & Noise in shadow areas limits effectiveness \\
\hline $10.60-12.51$ & TIR & 6 & $10 / 11$ & Some use for mapping thin debris-covered areas \\
\hline $\mathbf{0 . 5 0}-\mathbf{0 . 6 8}$ & Panchromatic & - & 8 & Manual delineation, sharpening of multispec. bands \\
\hline
\end{tabular}

Because snow and ice exhibit high reflectance in the visible bands and very low reflectance in the SWIR region, a majority of established techniques for glacier mapping rely on band ratios and indices. Paul et al. (2002a) explored the use of a TM4/TM5 band ratio for glacier mapping in the Swiss Alps and found success using threshold values of TM4/TM5 $=\sim 2.0$. For areas with deep topographic shadow effects, the TM3/TM5 ratio has proven to be effective, with some misclassification of water bodies as glacier (Paul and Kääb 2005). The normalized difference snow index (NDSI) has been successful in environments with extremely rugged topography, where soil, rock, snow, and cloud cover may cause confusion (Dozier 1989, Sidjak 1999). Silverio and Jaquet (2005) used the 
NDSI to map glaciers in the Cordillera Blanca in 1987 and 1996 Landsat TM imagery, selecting appropriate threshold values between $>0.52$ and $>0.4$ respectively. The NDSI can be calculated using TM2 and TM5 following Hall, Riggs and Salomonson (1995):

$$
\text { NDSI }=(\text { TM2 }- \text { TM5)/(TM2 }+ \text { TM5) }
$$

While these three band ratio/index products (TM3/TM5, TM4/TM5, and NDSI) are the most common techniques for glacier extent mapping using multispectral image data, a wide variety of other methods have been applied from unsupervised and supervised classification (Aniya et al. 1996, Li, Sun and Zeng 1998) to spectral mixture analysis (Klein and Isacks 1999) and fuzzy theory (Binaghi et al. 1997).

To reduce confusion and misclassification of other land cover types as glacier, it can be helpful to classify those areas and mask them out of further analysis (Pellikka and Rees 2009, Hendriks and Pellikka 2007). In heavily vegetated areas the normalized difference vegetation index (NDVI) can detect photosynthetic vegetation. The NDVI is calculated following Jensen (2007):

$$
\mathrm{NDVI}=(\mathrm{TM} 3-\mathrm{TM} 4) /(\mathrm{TM} 3+\mathrm{TM} 4)
$$

No discussion of remote sensing of glaciers would be complete without addressing the Global Land Ice Measurements from Space (GLIMS) project. The objectives of GLIMS are to establish and maintain a global GIS database of land ice to include surface topography, glacier extents, and surface velocities, and to facilitate the understanding of change dynamics of glacier areas included in the database (Bishop et al. 2004). Glacier inventories conducted within the framework of GLIMS use multispectral image data from moderate resolution platforms like the Advanced Spaceborne Thermal Emission and 
Reflectance Radiometer (ASTER) and Landsat as the principal data source for analysis of glacier conditions and change dynamics, but also seeks integration of auxiliary data from other sources, such as thermal, microwave, LiDAR, and Synthetic Aperture Radar (SAR) (Bishop et al. 2004). The GLIMS Analysis Tutorial provides guidance for researchers seeking to contribute to the inventory by defining key terms, image analysis procedures, feature attribution practices, etc. (Raup and Khalsa 2010). Image data and GIS shapefiles containing the glacier inventory data can be downloaded from the National Snow and Ice Data Center website (NSIDC 2015b). GLIMS glacier inventory data can serve as a suitable reference and validation dataset for subsequent remote sensing projects, with the understanding that the GLIMS data are generated for a specific image date, using a variety of techniques that may contrast with those of the proposed research itself. Fortunately GLIMS data is well-documented at the individual glacier level, and is explicit about the acquisition dates of imagery and the techniques used for glacier and debris-covered glacier extraction (Raup and Khalsa 2010).

\section{Remote Sensing of Debris-Covered Glaciers}

Manual delineation is widely considered the most accurate method of mapping debris-covered glacier areas from multispectral imagery, and even the most recent studies of glacial environments in the Cordillera Blanca rely on this technique (Burns and Nolin 2014) - a testament to the difficulty of automated mapping of DCGs in this area. Still, many efforts have been undertaken to develop a more sophisticated technique, both in the Cordillera Blanca and other regions. On balance, these efforts utilize some degree of data fusion, combining multispectral data with ancillary datasets like terrain data and thermal 
infrared imagery (Paul, Huggel and Kääb 2004, Shukla, Gupta and Arora 2010, Ranzi et al. 2004). Paul, Huggel and Kääb (2004) provide the most notable early example of this effort, employing multispectral data from ASTER and DEM data derived from ASTER stereoscopic bands to map DCGs in the Swiss Alps. The study uses decision-tree methodology to extract debris-covered glacier areas out of the data by process of elimination. The (TM4/TM5) band ratio provides segmentation of the study area into "glacier" and "other". From the "other" areas, a vegetation is classified with an intensity hue saturation (IHS) transformation image. Slope data is used to select all non-glacier and non-vegetation areas with a slope below the threshold of $24^{\circ}$, to be classified as "debris". Finally, a neighborhood analysis distinguishes debris areas with connectivity to glacier areas, which are classified as "debris-covered glacier". While the authors do not present a formal accuracy assessment, they note that their results provide "good correspondence" with a vector data set of "debris on glacier ice". They stress the importance of using the highest accuracy and finest spatial resolution DEM data available for the study area to achieve the best results.

Another prominent theme in the literature of remote sensing of DCGs is the use of thermal infrared (TIR) imagery in combination with multispectral and/or terrain data. Empirical studies have demonstrated that surface temperatures of ice-cored debris are lower than un-cored debris and bare rock by up to $\sim 4.5^{\circ} \mathrm{C}$ where ice-cored debris layers are less than $30 \mathrm{~cm}$ thick (Ranzi et al. 2004). A number of efforts have employed TIR data from Landsat and ASTER sensors to exploit this "thermal gap" (Shukla, Gupta and Arora 2010, Alifu, Tateishi and Johnson 2015). Taschner and Ranzi (2002) and Ranzi et al. (2004) achieve some success mapping DCGs in the Italian Alps using optical and thermal 
data, but find a debris depth of $40 \mathrm{~cm}-50 \mathrm{~cm}$ as a practical limitation on the use of these techniques. Shukla, Gupta and Arora (2010) note that while illumination effects of high topographic relief combined with low solar elevations can have a significant effect on surface temperatures observed in TIR data, the thermal gap between ice-cored debris and un-cored debris remains for both illuminated and shaded slopes.

In a notable recent study, Racoviteanu and Williams (2012) use a decision tree approach and a near exhaustive gamut of data including multispectral VNIR, SWIR, and TIR and DEM data from ASTER to classify debris-cover for ten glacier tongues in the Kangchenjunga area of the Himalaya. They also explore using Grey-Level CoOccurrence Matrix (GLCM) textural measures within debris-covered glaciers and other land-cover classes. Analysis of texture measures can be used to discriminate surface conditions like roughness and symmetry within an image (Racoviteanu and Williams 2012). GLCM texture measures, including mean, entropy, homogeneity, dissimilarity, etc. are statistical tools for characterizing the variance of brightness values over a portion of an image defined either by a region of interest (ROI) or a movingwindow/neighborhood analysis (Albregtsen 2008, Haralick, Shanmugam and Dinstein 1973). The authors compare a debris-covered glacier map manually delineated from texture images with the results of the decision tree classification and find an $+8 \%$ difference in total area as calculated by the texture-based method, and note that the texture analysis was most useful in areas where glacier termini were covered with thick layers of debris (Racoviteanu and Williams 2012). This suggests the potential value of GLCM texture measures in mapping DCGs in the Cordillera Blanca, where debris-cover is often quite thick. 


\section{Tree-Based Classifiers}

While much of the data fusion research in relation to DCGs has employed decisiontree methods or maximum likelihood classifiers (MLC) as the principal method of image classification, there is growing interest in the use of alternative classification techniques (Brenning 2009). Non-parametric tree-based classifiers are gaining consideration in remote sensing studies for their robust predictive capacity and their ability to integrate large multidimensional datasets that have multicollinearity amongst input covariates (Hansen, Dubayah and DeFries 1996). Two such methods are random forests and conditional inference trees (CTree) (Breiman 2001, Hothorn, Hornik and Zeileis 2006). Both methods make use of recursive partitioning of training data to develop tree-like models that seek to predict class membership with maximum homogeneity within classes and heterogeneity between classes.

CTree is a tree-based classification and regression model that integrates with the theory of conditional inference procedures (Hothorn, Hornik and Zeileis 2006). As with other classification and regression tree (CART) models, CTree uses binary recursive partitioning, where input cases are separated into increasingly homogenous nodes based on binary splits of individual predictor variables in a recursive fashion (Ishwaran and Rao 2009). At each node in the tree, splitting rules dictate how the cases are split into binary groupings by examining all possible splits and selecting the covariate demonstrating the best split (Hothorn, Hornik and Zeileis 2006).

Unique to CTree, conditional inference procedures add a measure of statistical rigor in the variable selection process by using conditional statistics at each split to measure the interaction between the dependent variable and predictor variables. Furthermore, CTree 
adds statistical tests to the stopping rules that dictate when the tree has reached maturity and no more splits should be made (Hothorn, Hornik and Zeileis 2006). These additional procedures result in a model with strong predictive performance while addressing the tendency for overfitting inherent in standard classification and regression tree models (Hothorn, Hornik and Zeileis 2006). Another advantage of the CTree model is the explicit nature of the variable selection process, and the resulting variable importance plots and tree diagram that detail split decisions and critical values of predictor variables upon which splits are made. For the present research this could prove very useful in understanding the specific conditions leading to the classification of image objects as DCG or other.

Random forests are another type of classification and regression tree algorithm, distinguished from CART and CTree models in that it is an ensemble method that utilizes the results of many decision trees in aggregate to achieve the best outcome for the overall classification (Horning 2010). Random forests are considered to be more robust than individual tree-based models, although they are "black box" models, being lesstransparent in terms of the structure of the individual trees within the ensemble (Breiman 2001). Random forests work by creating many (usually several hundred) decision trees and then applying each of those trees to each case in the dataset. Additionally, at each node in the tree a random subset of predictor variables is drawn for consideration as a split variable. By using only a random subset of predictor variables at each node in each tree, the algorithm ensures a higher level of distinctiveness between individual trees in the forest, reducing the overall error rate (Horning 2010). 
For classification of remote sensing data, cases are either individual pixels, or as in the present study, image objects with their associated ancillary covariates. Each tree will predict the class membership for each case, with the overall classification for that case being the class most often predicted by the sum of the trees in the forest (Horning 2010). For example if class "glacier" is predicted 75 times out of 100 trees, the random forest assigns class "glacier" to that case with a $75 \%$ probability. Thus, in addition to providing simple classification, random forests also attach a measure of uncertainty to the predictions they generate. Finally, the relatively simple nature of parameterizing the random forest model makes it attractive in comparison to other machine learning methods like boosting and support vector machines (Ghimire et al. 2012). The list of parameters that must be determined in a random forest model include: the training data, with selection of predictor variables (spectral features, terrain information, etc.) and dependent variables (i.e. land cover class); the desired number of trees to be generated; the number of predictor variables to be considered in each binary split decision; and parameters related to error estimation and variable significance (Horning 2010).

CTree and random forests both offer unique advantages that make them valuable for understanding debris-covered glaciers in the Cordillera Blanca. CTree provides an easily interpretable decision tree model complete with the critical values for split decisions that permit the inference of empirical values for covariates useful in describing DCGs.

Random forests provide a robust prediction of class membership as well as clear error estimation and variable importance information. The results of the two methods viewed side-by-side should produce a more complete picture of the phenomenon of DCGs than either one alone. 


\section{CHAPTER 2: METHODS}

\section{Study Area}

Located $400 \mathrm{~km}$ north of Lima, in the Ancash region of Peru, the Cordillera Blanca range extends $180 \mathrm{~km}$ north to south from $8^{\circ} 30^{\prime} \mathrm{S}$ latitude to $10^{\circ} 0^{\prime} \mathrm{S}$ (Figure 2.1). Over 200 summits in the Cordillera Blanca reach $5000 \mathrm{~m}$ or greater, with 27 topping $6000 \mathrm{~m}$ including Peru's tallest mountain, Huascarán Sur $(6768 \mathrm{~m})$. Glaciers occupy much of the highest areas from elevations of $3000 \mathrm{~m}$ and greater (Racoviteanu et al. 2008). Mountain glaciers in the Cordillera Blanca are characterized by steep, heavily crevassed slopes and are typically short in length (Silverio and Jaquet 2005, Kaser and Osmaston 2002). A recent advance and retreat of these glaciers has left behind small and vaguely defined lateral and frontal moraines, which may be prone to the formation of lakes. Over 60 valley glaciers, many with substantial debris cover, also reside in the Cordillera Blanca. Moraines produced by these valley glaciers are often quite large and well suited for the damming of glacial meltwater. A moraine of this nature is implicated in the 1941 Lake Palcacocha disaster, and still represents a significant potential flood hazard to area residents (Kaser and Osmaston 2002). 

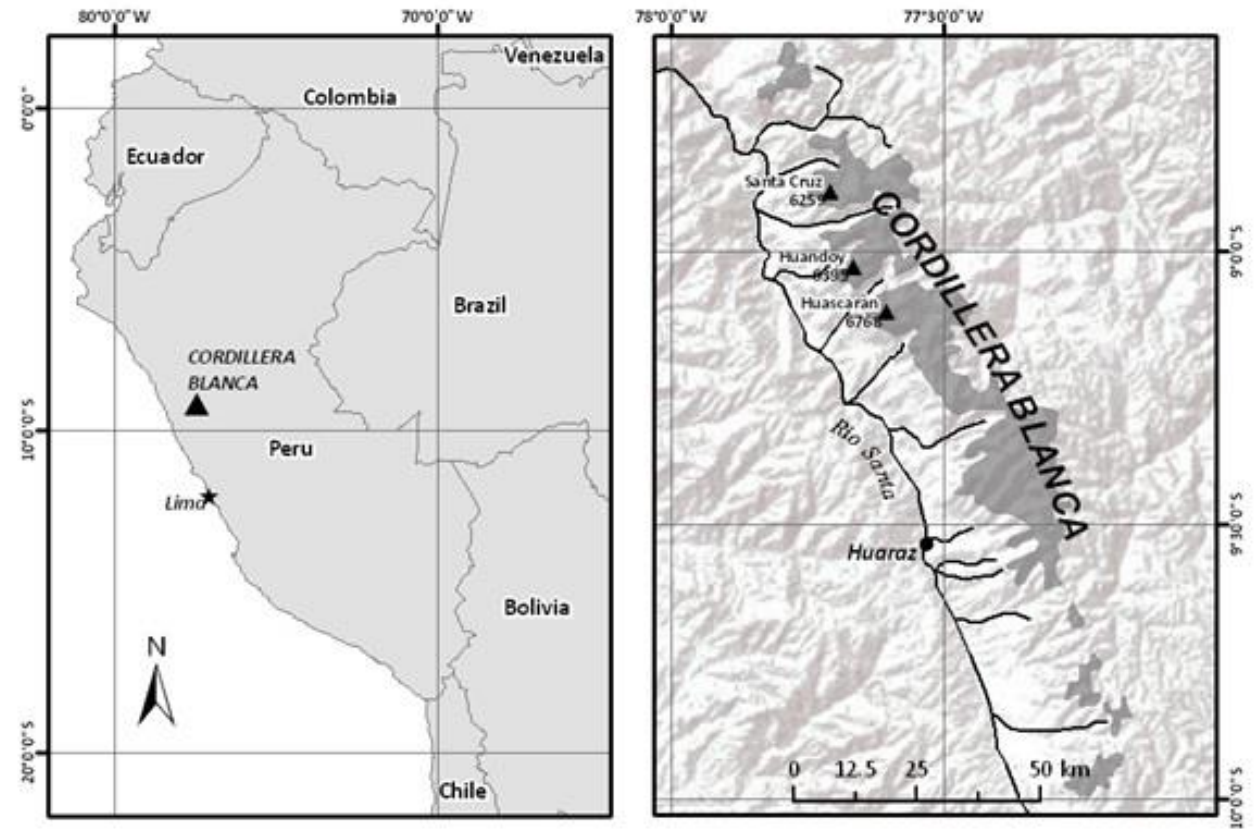

Figure 2.1 Study area: Cordillera Blanca region of Peru (Total Area: $\sim 3,400 \mathrm{~km}^{2}$ ).

Climate in the Cordillera Blanca is typical of locations in the outer tropical latitudes. Seasonal temperature variations are relatively small compared to diurnal fluxes, with seasons being better defined in terms of precipitation. The austral winter (May September) is typically dry with a majority of precipitation being received in the summer months (October - April). During these months the southward oscillation of the Intertropical Convergence Zone (ITCZ) draws in moist air masses from the Amazon Basin (Kaser and Osmaston 2002). Southeasterly winds carry air masses west, with windward eastern slopes receiving 2-3 times more precipitation than the leeward slopes of the western side (Johnson 1976). Intense solar radiation drives year-round ablation of glaciers, though higher rates of ablation occur during austral summer. Accumulation is mainly limited to the wet summer months, with extra-glacial snow cover usually melting within a few days after snowfall occurs (Silverio and Jaquet 2005). 


\section{Reference Data}

Reference data for this study come from two sources. The first source is the Global Land Ice Measurements from Space (GLIMS) Glacier Database. The GLIMS Glacier Database provides vector glacier extent data principally derived from ASTER and Landsat ETM+ imagery (Bishop et al. 2004). The GLIMS database includes polygon and attribute data identifying debris-covered glacier areas, making these data useful as a reference and validation dataset. GLIMS data for the study area were downloaded from the National Snow and Ice Data Center's online data clearinghouse in GIS shapefile format (NSIDC 2015b). The attribute information for polygons identified as "debriscovered glacier" in the GLIMS data indicate that there are two sets of DCG polygons covering the Cordillera Blanca region, one digitized from 2003 imagery from the French Satellite Pour l'Observation de la Terre (SPOT), and another digitized from 2005 ASTER imagery (NSIDC 2015b). Visual analysis of the two datasets revealed that the polygons derived from the 2003 SPOT imagery are more complete and better reflect the true boundaries of DCGs than the alternative dataset. As a result, SPOT-derived polygons were the main source of validation while the ASTER-derived data were used only where necessary due to data gaps.

\section{Manual Delineation}

The second source of reference data is an inventory of DCGs manually delineated from high resolution Google Earth ${ }^{\mathrm{TM}}$ and Bing Maps ${ }^{\mathrm{TM}}$ imagery. Google Earth $^{\mathrm{TM}}$ and Bing Maps ${ }^{\mathrm{TM}}$ provide a free source of very high resolution image data with worldwide coverage, but images comprising the mosaic for a particular area may have been acquired 
on different dates, sometimes with disparities of over one year between conterminous image tiles. In dynamic environments like the Cordillera Blanca, temporal variability in environmental conditions between images in the mosaic, and between the mosaic data and the Landsat OLI data selected for study may be significant. Care was taken to utilize imagery from Google Earth ${ }^{\mathrm{TM}}$ and Bing Maps ${ }^{\mathrm{TM}}$ that most closely matched the date of acquisition of the Landsat OLI data. A majority of the Bing Maps imagery was acquired in June 2010, July 2012, or June 2013 , while Google Earth ${ }^{\mathrm{TM}}$ imagery was generally acquired in either August 2013 or June 2015 (van Exel 2010, Google 2015). This data is the most accurate and representative reference data available given the constraint of available resources.

With the assistance of an expert with knowledge of the study area, and using visually identifiable DCG features like hummocky topography, ice cliffs, and supraglacial lakes, boundaries of DCGs were manually delineated at a map scale of 1:4000 in the ArcGIS software package environment using very high resolution ( $\sim 0.5 \mathrm{~m} /$ pixel) Bing Maps ${ }^{\mathrm{TM}}$ aerial imagery as the principal source (ESRI 2014). GLIMS debris-covered glacier polygon data were used as a guide to help locate previously identified DCGs. However, as GLIMS data were generated from moderate resolution imagery acquired a decade prior, it was assumed that there would be some discrepancies in the DCGs identified in the GLIMS data and the present survey due to the increased resolution of the Bing Maps $^{\mathrm{TM}}$ imagery and changes in the study area environment in the intervening years. Google Earth ${ }^{\mathrm{TM}}$ imagery was utilized primarily as an ancillary dataset to clarify and/or verify the results of digitization over the Bing Maps ${ }^{\mathrm{TM}}$ imagery in areas where cloud contamination or poor image quality presented challenges. 
The manual delineation of DCGs even by a trained analyst can be somewhat subjective in terms of the absolute position of glacier boundaries. To address this uncertainty, three repeat delineations, each performed 24 hours apart, of five DCGs of various sizes distributed along the longitudinal axis of the Cordillera Blanca range were completed according to the best practices in Paul et al. (2013). For each glacier sampled, the standard deviation of the areas resulting from each repeat digitization was calculated and expressed as a percentage of the mean area for that glacier. Finally, the mean of the standard deviations for the five glaciers sampled was computed and serves as a measure of the accuracy of the manual delineation technique (Paul et al. 2013).

\section{Image Data}

Landsat 8 OLI multispectral data have a nominal spatial resolution of 30 meters, with five spectral bands located in the visible and near-infrared region (VNIR), two shortwave infrared (SWIR) bands, a cirrus cloud detection band, a 15-meter resolution panchromatic band, and two 100-meter (resampled to 30 meter) thermal infrared (TIRS) bands (USGS 2015). Table 2.1 shows OLI spectral bands and their respective bandwidths.

Table 2.1 Landsat OLI bands

\begin{tabular}{|c|c|c|c|}
\hline Band Number & Band Name & Wavelength & Resolution (m) \\
\hline 1 & Coastal aerosol & $0.43-0.45$ & 30 \\
\hline 2 & Blue & $0.45-0.51$ & 30 \\
\hline 3 & Green & $0.53-0.59$ & 30 \\
\hline 4 & Red & $0.64-0.67$ & 30 \\
\hline 5 & Near Infrared (NIR) & $0.85-0.88$ & 30 \\
\hline 6 & SWIR 1 & $1.57-1.65$ & 30 \\
\hline 7 & SWIR 2 & $2.11-2.29$ & 30 \\
\hline 8 & Panchromatic & $0.50-0.68$ & 15 \\
\hline 8 & Cirrus Cloud & $1.36-1.38$ & 30 \\
\hline 10 & Thermal IR 1 & $10.60-11.19$ & $100(30)$ \\
\hline 11 & Thermal IR 2 & $11.50-12.51$ & $100(30)$ \\
\hline
\end{tabular}


A Landsat 8 OLI scene from World Reference System (WRS2) path 08 and row 66, acquired July $12^{\text {th }}, 2014$, was downloaded from the United States Geological Survey (USGS) Earth Resources Observation and Science (EROS) Center using the USGS EarthExplorer tool. The data were received in the Geotiff format and came orthorectified and projected in the Universal Transverse Mercator (UTM) coordinate system, zone 18 south. This image was selected due to its acquisition date falling within the local dry season when glacier extents are most visible and snow cover is at or near annual minimums. Visual inspection of the image also confirms that it contains negligible cloud contamination and limited seasonal snow cover in the study area (Figure 2.2). The extent of this scene provides full coverage of the Cordillera Blanca with the exception of a small area at the southern margin of the range. This study excludes that area to avoid the complications of mosaicking datasets, and because GLIMS data showed no DCGs in this portion of the range. 


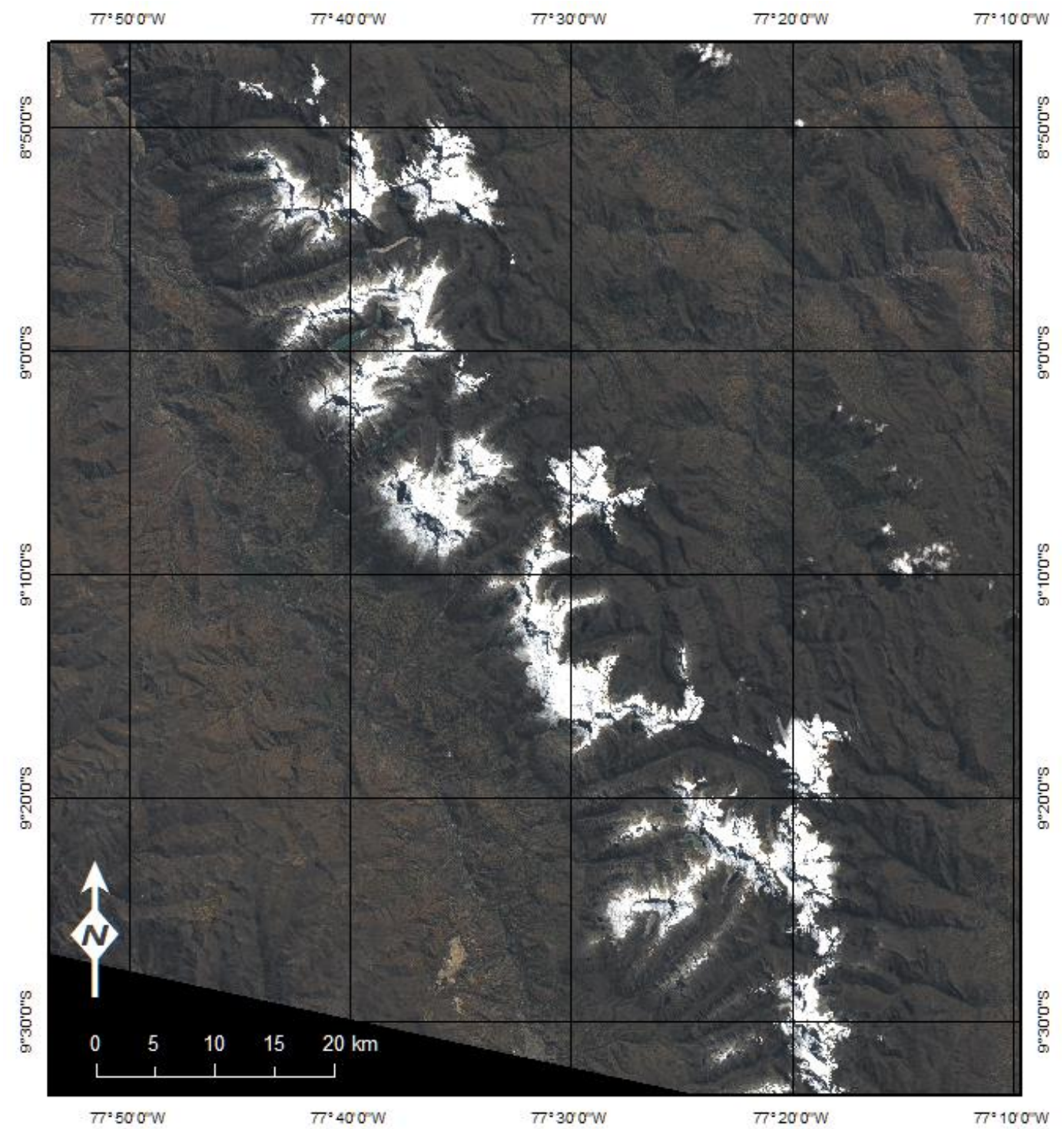

Figure 2.2 Pan-sharpened Landsat OLI true color composite (RGB: Landsat OLI 4-32) image of Cordillera Blanca range for July 12, 2014.

\section{Image Preprocessing}

Recent research has demonstrated the value of performing atmospheric corrections of satellite data before use in glaciological applications (Burns and Nolin 2014). For the present research, the Landsat OLI scene was first converted from raw digital numbers (DNs) to at-sensor radiance using the Radiometric Calibration tool in the Environment for Visualization of Imagery (ENVI) v5.1 software package (Exelis Visual Information 
Solutions, Boulder, Colorado). Radiance data were then converted to surface reflectance using the Modtran4-based Fast Line-of-sight Atmospheric Analysis of Hypercubes (FLAASH) atmospheric correction module in ENVI (Felde et al. 2003). Independently, Landsat thermal band 10 was converted to at-sensor radiance, and then to at-sensor brightness temperature using the method recommended by the United State Geological Survey (USGS 2013).

In order that the image segmentation algorithm result in accurate and representative image objects, the Landsat OLI visible and near-infrared (VNIR) bands were submitted to the Gram-Schmidt pan-sharpening algorithm in ENVI (Laben and Brower 2000). Pansharpening is a resolution merging procedure that resamples lower resolution multispectral bands to a higher-resolution panchromatic band using the cubic convolution algorithm. In this instance, 30 meter Landsat OLI VNIR bands were pan-sharpened using the 15 meter Landsat OLI panchromatic band, resulting in a four band, 15 meter multispectral image.

\section{Terrain Data}

For the representation of elevation and other terrain information, a digital elevation model (DEM) acquired during the Shuttle Radar Topography Mission (SRTM) was downloaded from the Consultative Group for International Agriculture Research Consortium for Spatial Information (CGIAR) website (Jarvis et al. 2008). SRTM data were received in GeoTiff format with a nominal resolution of 90 meters, and projected in the UTM zone 18 south coordinate system. The original SRTM data distributed by NASA often contain voids in rugged, high relief areas such as the Cordillera Blanca. 
CGIAR distributed SRTM data have been void-filled using auxiliary elevation data to produce a continuous surface which is free of data gaps (Jarvis et al. 2008).

Alternative DEM data sets considered for use in analysis include a 30 meter resolution version of the SRTM DEM data for all of South America, released at the end of 2014 by NASA. While the improved resolution of this product held appeal, significant data gaps and abnormalities rendered it unsuitable for the study area. Also considered for use in this research was the ASTER Global DEM (GDEM2). ASTER GDEM2, a product of the stereoscopic capabilities of the ASTER sensor, also offer resolution of 30 meters and worldwide coverage (Kääb et al. 2002). Unfortunately GDEM2 data often suffer from significant artifacts and inconsistencies in high relief areas. Other research utilizing digital elevation data for glaciological applications have noted the challenges and errors associated with the GDEM2 product (Racoviteanu et al. 2007, Kääb et al. 2002). Review of the available GDEM2 data available for the Cordillera Blanca region confirmed that it exhibits artifacts that make it unsuitable for this study.

SRTM digital elevation data were imported into the ArcGIS Desktop software package and clipped to the spatial extent matching the Landsat OLI scene. A number of derivative datasets were created from the DEM data using the Spatial Analyst tools in ArcGIS: a slope raster (in degrees), an aspect raster (in degrees), and a curvature raster (in radians/meter). The slope raster was resampled to 15 meters using the cubic convolution method, in order to match the pan-sharpened Landsat OLI VNIR data to be used in the image segmentation process. 


\section{Image Segmentation}

Object-based image analysis begins with the segmentation of image data into image objects. Image objects are defined by a segmentation algorithm that classifies images into discrete groups of pixels based on some measure of homogeneity. Though many techniques exist for the purpose of image segmentation, the multiresolution segmentation algorithm has gained widespread acceptance in recent years for use in multispectral remote sensing applications (Blaschke et al. 2000, Benz et al. 2004). The multiresolution segmentation (MS) algorithm is a region-growing technique that begins by assessing each pixel in an image as a separate object and iteratively merging adjacent objects into larger and larger objects, based on local homogeneity criteria (Baatz and Schäpe 2000).

Segmentation parameters - the scale parameter, shape/color parameter, and compactness/smoothness parameter - define homogeneity criteria and dictate the size and shape of the objects in the final iteration of region-merging. Region-growing terminates when the homogeneity of image objects exceeds the scale parameter (SP), an abstract value the magnitude of which determines the maximum size of image objects (Baatz and Schäpe 2000). A larger SP will result in larger resulting image objects, and vice-versa. The color parameter defines the influence of pixel values on region-merging decisions and is derived from the weighted sum of standard deviations of spectral bands within image objects (Baatz and Schäpe 2000). The shape parameter is a composite of smoothness and compactness. Compactness refers to the ratio of an image object's perimeter to its area while smoothness refers to the relationship of an image object boundary's shape to that of a perfect square (Baatz and Schäpe 2000). The shape and color parameters are related in that their total value must be equal to one. If the shape 
parameter is 0.4 , the shape parameter must 0.6 . The same is true for smoothness and compactness.

The process of determining the optimal values for segmentation parameters is often qualitative and subjective. It is common practice to run the segmentation algorithm using a variety of scale parameters, selecting the most appropriate based on visual analysis of the resulting image objects (Meinel and Neubert 2004). Color and shape parameters are evaluated in a similar fashion. Rather than simple trial and error, this study used an approach that evaluated segmentation parameters based on regular intervals defined for each parameter, and selected the optimal combination of values based on best conformity of resulting image objects to features visually identified as debris-covered glaciers. The higher resolution pan-sharpened Landsat OLI bands, as well as the resampled 15 meter slope raster, were the only data layers employed in image segmentation as the scale parameter is dependent upon the resolution of input layers.

The range of scale parameters from 2 to 20 were explored iteratively in increments of two. At the minimum value of 2 , image objects may contain just a few pan-sharpened Landsat OLI pixels, and are too small to effectively represent any features of interest in the imagery (Figure 2.3a). At the other extreme, a scale parameter of 20, image objects have grown so large that they may contain more than one land cover class (Figure 2.3b). After stepping through the full range of values, a scale parameter of 12 was determined to be the most appropriate for this study. 

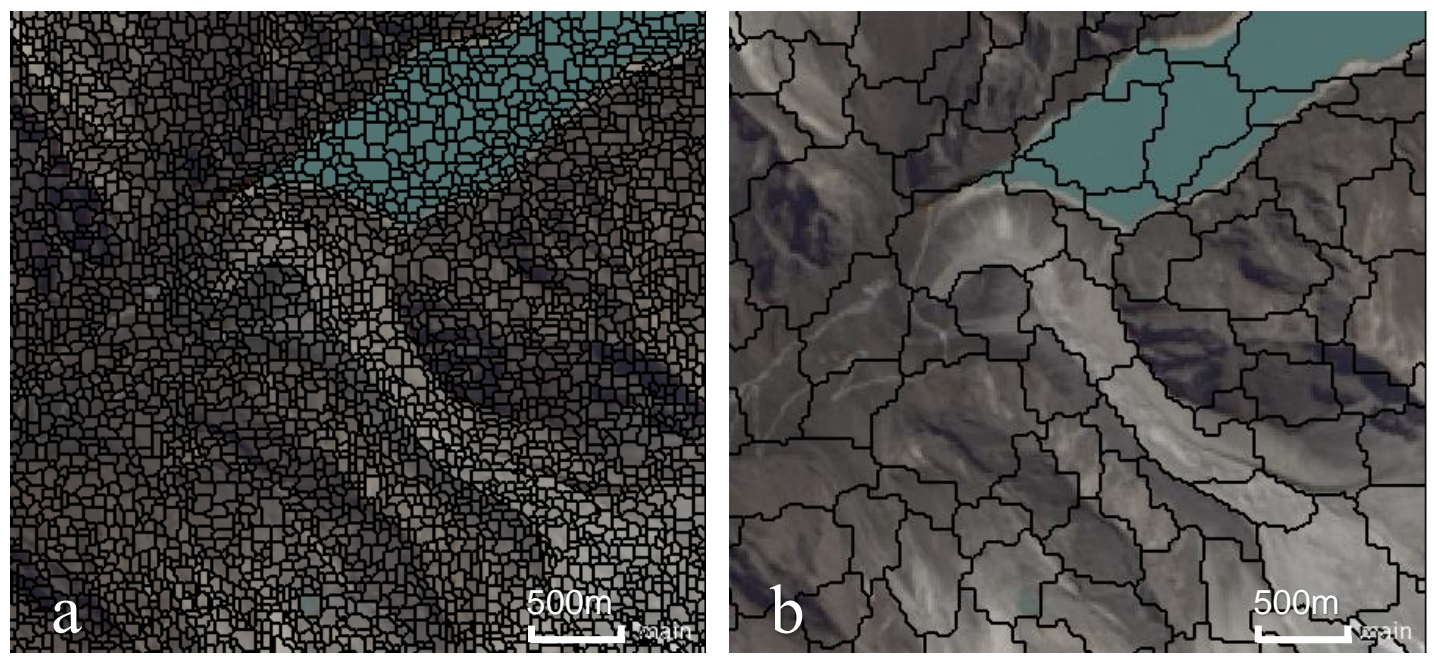

Figure 2.3 Segmentation demonstrating effects of scale parameter. Subset of study area containing the Jatunraju debris-covered glacier tongue. Scale parameter: $\mathrm{a}=2, \mathrm{~b}=20$.

Values for the shape/color parameter ranging from shape $=0.1 /$ color $=0.9$ to shape $=$ $0.9 /$ color $=0.1$ in increments of 0.1, were tested for the study area. At the minimum value of this range (Figure 2.4a), color has the greatest influence on image objects and resulting objects are free to grow sinuously to maximize homogeneity of image spectral values. At the other extreme (Figure 2.4b) the importance of color is minimized, and more influence is given to the uniformity of image shape, which is regulated by the compactness/ smoothness parameter discussed in the next section. Debris-covered glaciers do not generally demonstrate a regular shape, so a relatively low weight for the shape parameter of 0.3 (color 0.7 ) was selected. 

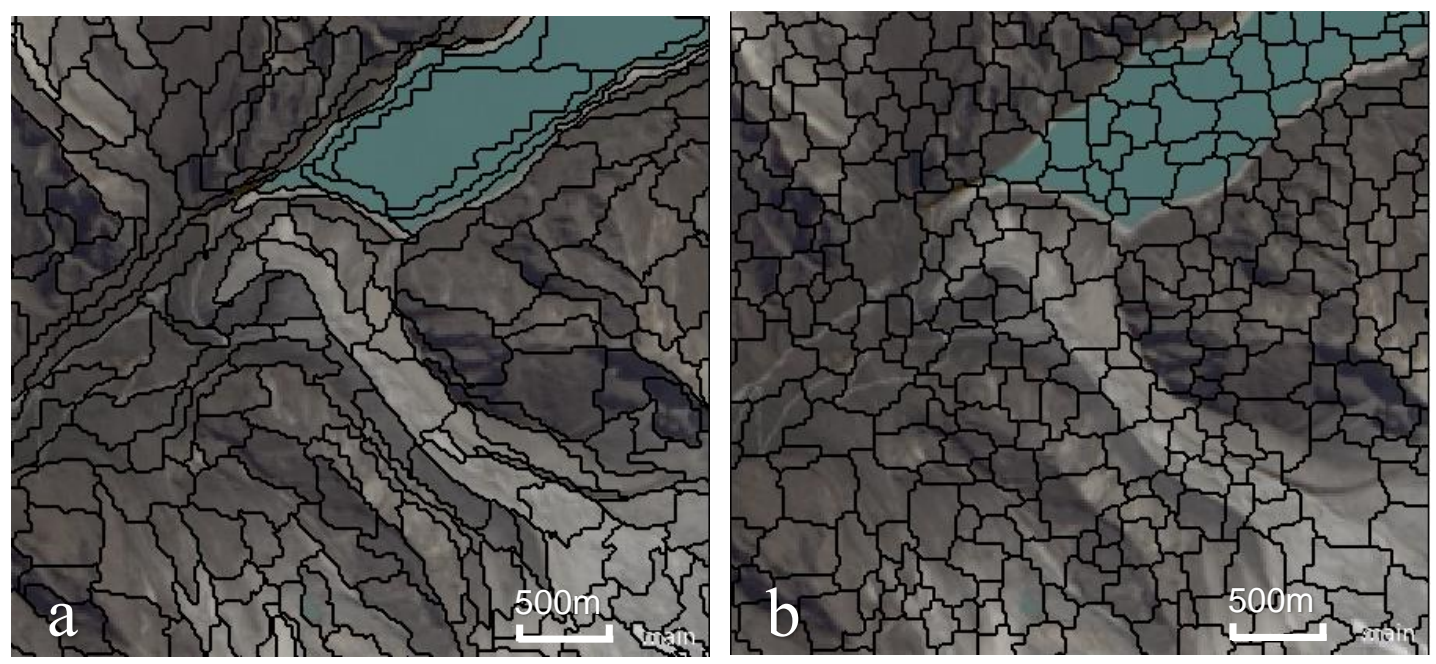

Figure 2.4 Segmentation demonstrating effect of shape parameter. Subset of study area containing the Jatunraju debris- covered glacier tongue. Shape parameter: $\mathrm{a}=0.1, \mathrm{~b}=0.9$.

Finally, values ranging from compactness $=0.1 /$ smoothness 0.9 to compactness $=0.9$ /smoothness 0.1 were tested iteratively in increments of 0.1 . Lower compactness (and thus higher smoothness) values allowed objects to grow longer and narrower (Figure 2.5a), while conversely increasing the value for compactness minimized the perimeter/area ratio of image objects and resulted in compact, regular objects as demonstrated in Figure 2.5b. A low compactness value of $0.2 /$ smoothness 0.8 was considered to be optimal here, largely due to the phenomenon of elongated units of relatively homogenous slope values observed for DCGs in the study area. 

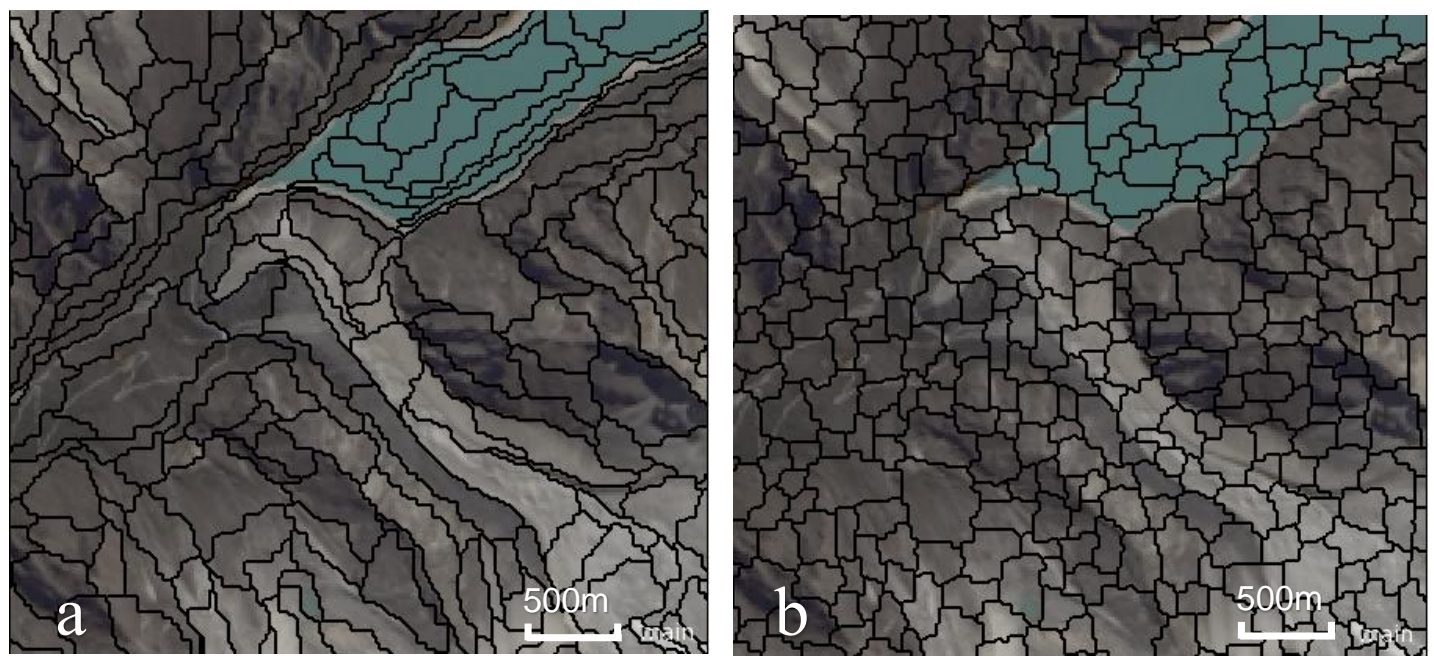

Figure 2.5 Segmentation demonstrating effects of compactness parameter. Subset of study area containing the Jatunraju debris- covered glacier tongue.

Compactness parameter: $\mathrm{a}=0.1, \mathrm{~b}=0.9$.

\section{Initial Classification}

An exploratory visual analysis of the image and terrain data was conducted following the final image segmentation, and 30 unique image object features were generated to characterize various dynamics associated with the study area environment (Table 2.2). These features included: spectral derivatives like band ratios, indices, and transformations; simple statistics regarding data values within image objects, such as mean values and standard deviations; and textural features like grey-level covariance matrix (GLCM) homogeneity, contrast, and dissimilarity (Trimble 2012). For each of the input bands (Landsat OLI bands, and the terrain variables elevation, slope, aspect, and curvature), image object mean and standard deviation features were calculated.

Additionally, to identify clean glacial ice and snow two spectral derivative features were generated: the TM4/TM5 band ratio, and NDSI. Similarly, NDVI features were generated for classification of vegetated. An RGB to intensity, hue, and saturation (IHS) transformation was also calculated, resulting in one feature for each of the three 
components of the transformation. Finally, five textural features were created: GLCM homogeneity, GLCM dissimilarity, GLCM contrast, GLCM energy, and GLCM entropy.

Table 2.2 Image object features

\begin{tabular}{|c|c|c|}
\hline Data Source & Class & Features \\
\hline OLI Blue & Spectral & Mean \& StdDev Blue \\
\hline OLI Green & Spectral & Mean \& StdDev Green \\
\hline OLI Red & Spectral & Mean \& StdDev Red \\
\hline OLI NIR & Spectral & Mean \& StdDev NIR \\
\hline OLI SWIR1 & Spectral & Mean \& StdDev SWIR1 \\
\hline OLI SWIR2 & Spectral & Mean \& StdDev SWIR2 \\
\hline OLI TIR & Spectral & Mean \& StdDev Brightness Temp \\
\hline OLI Red \& NIR & Ratio/Index & Mean \& StdDev NDVI \\
\hline OLI Green \& SWIR & Ratio/Index & Mean \& StdDev NDSI \\
\hline OLI NIR \& SWIR & Ratio/Index & Mean \& StdDev NIR/SWIR \\
\hline OLI Visible Bands & Transform & Mean IHS Hue Component \\
\hline SRTM Slope & Terrain & Mean \& StdDev SRTM Slope \\
\hline SRTM Aspect & Terrain & Mean \& StdDev SRTM Aspect \\
\hline SRTM Curvature & Terrain & Mean \& StdDev SRTM Curvature \\
\hline SRTM Elevation & Terrain & Mean \& StdDev SRTM Elevation \\
\hline & Textural & GLCM Homogeneity \\
\hline & Textural & GLCM Dissimilarity \\
\hline & Textural & GLCM Contrast \\
\hline & Textural & GLCM Energy \\
\hline & Textural & GLCM Entropy \\
\hline
\end{tabular}

While the ultimate objective of the image classification process is the discrimination of debris-covered glaciers, it is useful at first to mask out the areas that can be positively identified as "non-debris-covered glacier". Two major land-cover classes with clear spectral signals - clean ice and snow (class "glacier"), and vegetated slopes (class "vegetation") - were identified using the Feature View in eCognition. Figure 2.6 provides an example of this interactive density-slicing applied to the TM4/TM5 ratio. Initial classification of glacial ice and snow, and vegetated areas was performed in eCognition 
using class membership rules based on the threshold values of TM4/TM5 $>2.0$ for glacier and NDVI $>0.1$ for vegetation.

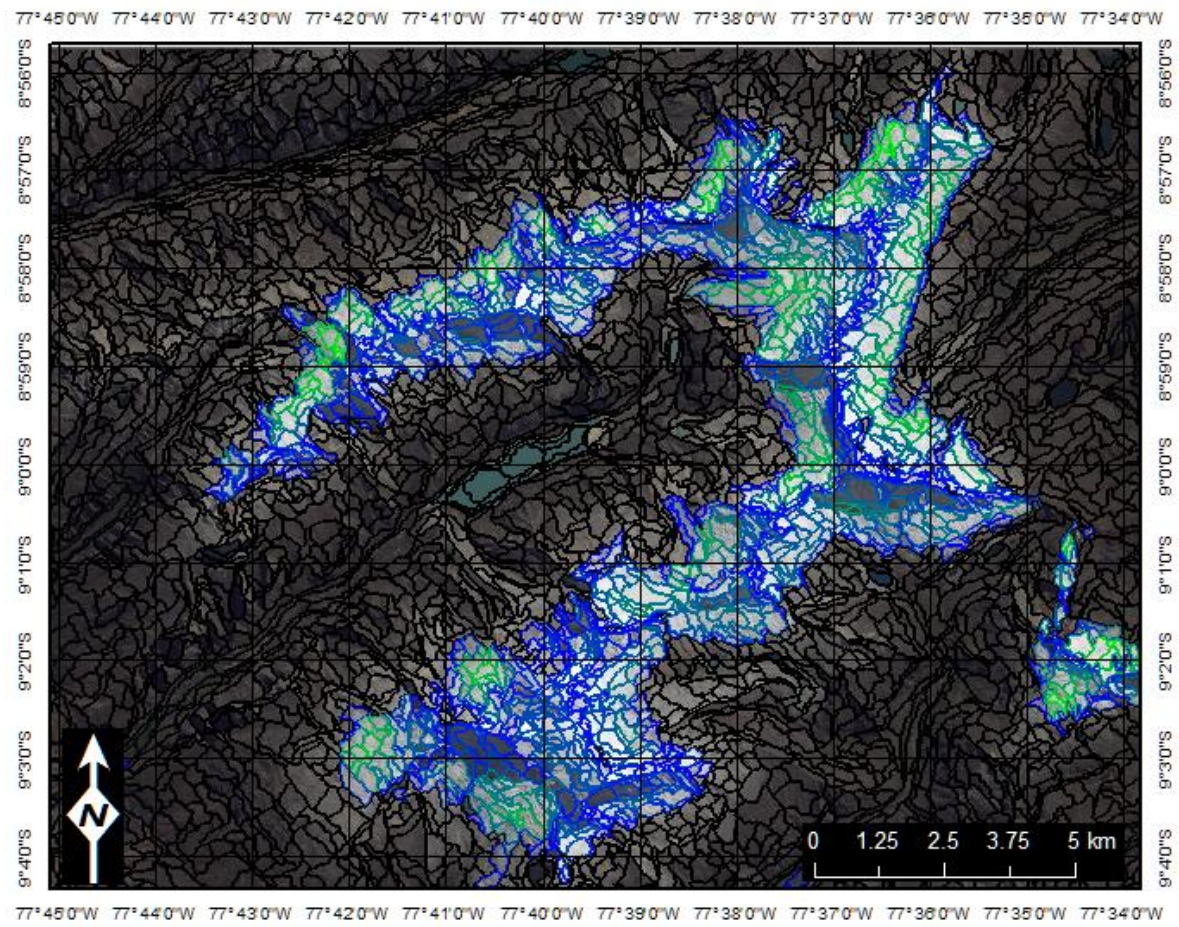

Figure 2.6 eCognition Feature View. Subset of study area centered on Laguna Parón and the Huandoy Massif. Image objects are color coded based on their TM4/TM5 ratio. Values below the minimum threshold are black, above the maximum threshold are white, and within the threshold range are dark blue to light green.

\section{Tree-based Classifiers}

After masking out glacier ice and vegetation, the two tree-based classifiers - random forests and conditional inference trees - were applied to the remaining image objects (Hothorn et al. 2015, Breiman 2001). Tree-based classifiers require a sample of training data to build their predictive models. To capture the dependent variable for the training data, the unclassified image object polygons were intersected with the manually derived DCG polygons. A 70\% random sample dataset containing predictor variables (image 
object feature values) and the dependent variable (DCG presence/absence), was generated as training data for classification. The remaining $30 \%$ was held out of the training data to be used for validation of classification results.

The random forests classification used the implementation included in the 'randomForest' package v1.0-21 for the R statistics programming environment to predict class membership for the original complete image objects in the study area (R Core Team 2015). After initial data tidying within $\mathrm{R}$ a random forests model was fitted to the training data using the tuneRF function. The number of trees was set to 500, which proved to provide enough iterations to minimize classification errors. For each individual tree in the random forest, the algorithm draws two-thirds of the user-input training data as a random sample and uses that sample to generate a tree. The remaining training data initially held out - the out-of-bag (OOB) sample - is then classified to cross-validate the resulting tree. The rate of misclassification of this cross-validated data is the out-of-bag (OOB) error rate (Breiman 2001). For variable selection, the tuneRF algorithm optimizes the model by iteratively varying the number of predictor variables (the "mtry" value) available for split decisions at each node. For each successive mtry value the algorithm calculates OOB error rate and chooses the mtry value with the lowest error rate (Liaw and Wiener 2002). The tuneRF algorithm determined an optimal mtry value of 8 variables.

The random forest algorithm also determines the importance of individual predictor variables. For each tree, a random predictor variable is selected and its values randomly permuted across cases in the out-of-bag sample, which is then reclassified by the same tree. The OOB error from the classification using the permuted data is calculated and compared to the actual OOB error of the tree. If the permutation of values results in 
dramatic changes to the classification results, it can be inferred that the variable in question is of great importance to the model. If permutation results in little change in classification accuracy, the variable has relatively lesser importance for prediction performance. Variable importance for the entire forest is measured by calculating the mean decrease in accuracy (increase in $\mathrm{OOB}$ error rate) for each predictor variable in the forest (Breiman 2001).

The same training data used in the random forests classification were then applied to the $\mathrm{C}$ Tree classifier. The $\mathrm{C}$ Tree model includes the option to use variable randomization similar to the random forests model (Hothorn et al. 2015), and thus the optimal mtry value identified from the tuneRF function described above was used to match the CTree model as closely as possible to the random forests model. For a comprehensive summary of the workflow of the classification procedures described above, the resulting $\mathrm{R}$ programming code has been included as Appendix A.

\section{Accuracy Assessment}

To evaluate the accuracy of the two classifications, error plots comparing the predicted class memberships to the actual class memberships in the reference data were generated in R (see code in Appendix A), and full error matrices including user's and producer's accuracy, false positive rates, and overall classification accuracy statistics were calculated for better understanding of the nature of the errors (Congalton 1991). An error matrix is a table that presents the expected classification of a reference/validation dataset versus the predicted classification results. 
The user's accuracy describes the errors of commission made by the classifier (i.e. false positives) and is calculated on a per-class basis as (Story and Congalton 1986):

$$
U_{\text {ser }}^{\prime} \text { s Accuracy }=\frac{\# \text { of objects correctly classified as class } Y}{\text { Total \# of objects classified as class } Y}
$$

The producer's accuracy describes errors of omission and is calculated and is calculated on a per-class basis as (Story and Congalton 1986):

$$
\text { Producer's Accuracy }=\frac{\# \text { of objects correctly classified as class } Y}{\text { Total } \# \text { of objects of class } Y \text { in reference data }}
$$

The overall classification accuracy statistic describes the overall rate of correct classifications across all classes. It is calculated as (Story and Congalton 1986):

$$
\text { Overall Accuracy }=\frac{\# \text { of objects correctly classified in all classes }}{\text { Total number of objects classified }}
$$

An additional accuracy metric, the Kappa statistic, was also calculated from the error matrices for each of the two classifications. Kappa is a single statistic that incorporates all of the information within an error matrix, making it a comprehensive measure of accuracy that can facilitate comparison across different error matrices (Congalton 1991). The Kappa statistic is calculated as,

$$
K=\frac{N \sum_{i=1}^{r} x_{i i}-\sum_{i=1}^{r}\left(x_{i+} * x_{+i}\right)}{N^{2-} \sum_{i=1}^{r}\left(x_{i+} * x_{+i}\right)}
$$

where $r$ is the number of rows in the matrix, $x_{i i}$ is the number of cases in row $i$ and column $i, x_{i+}$ and $x_{+i}$ are the marginal totals of row $i$ and column $i$, respectively, and $N$ is the total number of cases (Congalton 1991).

Another measure of accuracy that can be useful in situations where the land cover of interest occupies a small percentage of the total study area is to examine the false positive rate (FPR) in context of the sensitivity rate achieved by a classifier (Brenning 2009). The 
sensitivity rate, which in a binary classification is equivalent to the producer's accuracy for positive cases, measures the percentage of positive cases in the training data that are accurately classified (Hand 1997). The FPR represents the percentage of negative cases from the training data that are incorrectly classified as positive (Hand 1997). Comparing the FPR in relation to the sensitivity rate provides a measure of the accuracy of the classifier at the expense of errors of commission. The FPR can be calculated from the producer's accuracy for negative cases as follows:

$$
F P R=100-\text { Producer's accuracy for negative cases }
$$

In addition to the calculation of traditional accuracy statistics described above, a qualitative visual interpretation of the classification results was undertaken in ArcGIS Desktop by mapping the predicted class memberships of image objects in relation to the manually delineated DCG reference polygons. Visual interpretation facilitated the analysis of spatial patterns of error that were not obvious in the traditional accuracy assessment metrics. 
CHAPTER 3: RESULTS

\section{Manual Delineation}

The visual survey of the debris-covered glaciers in the Cordillera Blanca region yielded 37 DCGs totaling an area of $14.4 \mathrm{~km}^{2}$. Hummocky terrain, lobate features, and supraglacial lakes in close proximity to clean glacier ice were all considered to be indicators of debris-covered glacier. Interestingly, many of the debris-covered glaciers identified in the GLIMS data, when viewed against the very high resolution Bing Maps ${ }^{\mathrm{TM}}$ imagery, did not exhibit the characteristic indicators of DCGs. As a result there were differences between the manually-delineated DCGs and the GLIMS data in terms of both the number and area of DCGs identified in the study area. Table 3.1 provides details of the DCGs identified in the GLIMS data compared to the present survey.

Table 3.1 Results of manual delineation of DCGs vs. GLIMS database.

\begin{tabular}{|c|c|c|c|}
\hline DCG Polygons & \# of DCGs & Area of DCGs & Image Source \\
\hline GLIMS (2003) & 47 & $17.8 \mathrm{~km}^{2}$ & SPOT \\
\hline GLIMS (2005) & 37 & $16.1 \mathrm{~km}^{2}$ & ASTER \\
\hline Biddle (2014) & 37 & $14.4 \mathrm{~km}^{2}$ & Bing Maps \\
\hline
\end{tabular}

The mean standard deviation of the areas of the five glaciers sampled for repeat delineation was $6.7 \%$. This value serves as a measure of the accuracy of area calculations derived from manually delineated DCG boundaries. Applying this error term to all DCGs identified in the survey results in an estimated total area of DCGs of $14.4 \mathrm{~km}^{2} \pm 0.97 \mathrm{~km}^{2}$. The full statistical results from the repeat delineations are presented in Table 3.2, and a 
visual example of the repeat delineations for a selected DCG are depicted in Figure 3.1.

Results suggest that the while some DCG boundaries are quite clear in very high resolution imagery, others are more nebulous. This is particularly true where DCGs are adjacent to lateral moraines that have a similar appearance in color and texture.

Table 3.2 Statistics from the repeat digitization of five selected DCGs.

\begin{tabular}{|c|c|c|c|c|c|}
\hline Glacier & $\begin{array}{c}\text { Min Area } \\
\left(\mathbf{k m}^{2}\right)\end{array}$ & $\begin{array}{c}\text { Max Area } \\
\left(\mathbf{k m}^{2}\right)\end{array}$ & $\begin{array}{c}\text { Mean Area } \\
\left(\mathrm{km}^{2}\right)\end{array}$ & Std Dev. $\left(\mathrm{km}^{2}\right)$ & Std Dev (\%) \\
\hline 1 & 0.08478 & 0.08995 & 0.087 & 0.0027 & 3.103 \\
\hline 2 & 0.13508 & 0.15265 & 0.1457 & 0.0093 & 6.383 \\
\hline 3 & 0.26347 & 0.28734 & 0.2776 & 0.0125 & 4.503 \\
\hline 4 & 0.43851 & 0.54044 & 0.4773 & 0.0552 & 11.57 \\
\hline 5 & 1.49502 & 1.71102 & 1.5695 & 0.1226 & 7.811 \\
\hline
\end{tabular}

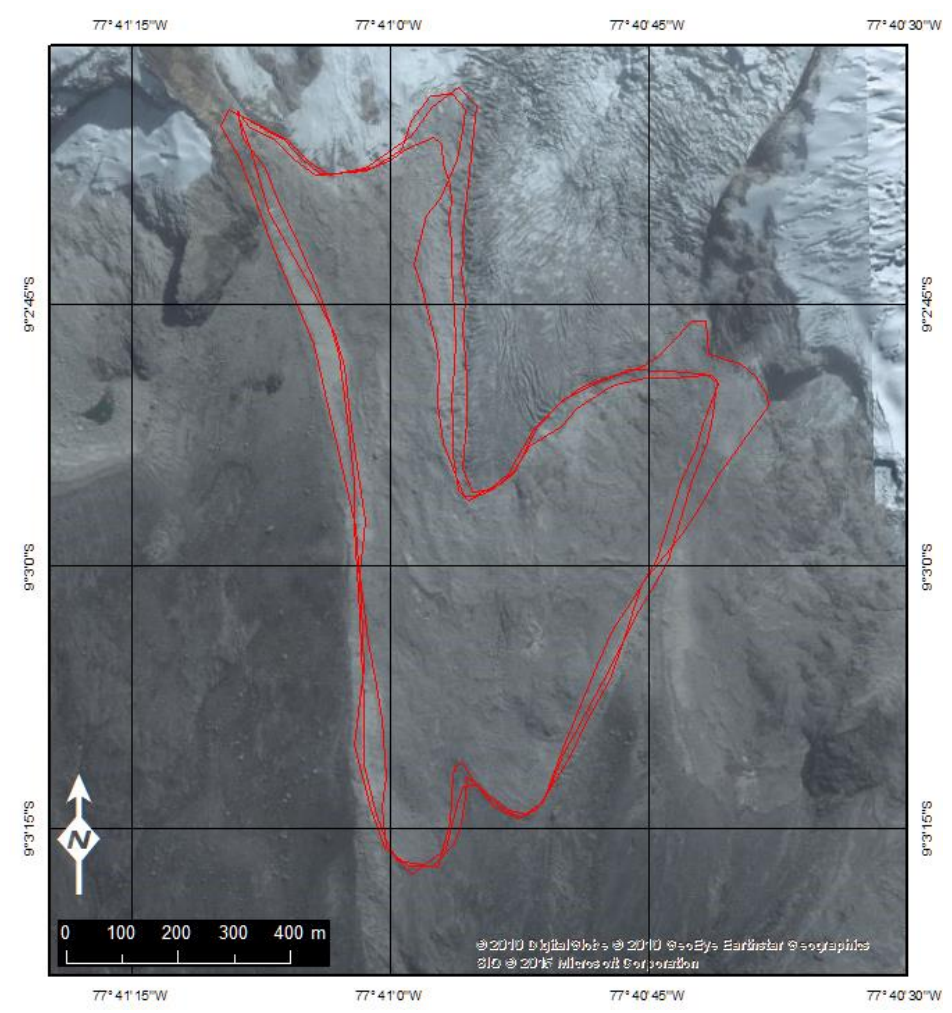

Figure 3.1 Debris-covered glacier boundaries from repeat manual delineations for subset of one DCG, demonstrating the potential variation in the position of DCG boundaries interpreted on separate occasions by the same analyst. 


\section{Image Segmentation}

Iterative testing of segmentation parameters resulted in the final selection of scale $=$ 12 , shape $=0.3$, and compactness $=0.2$, which provided the best visual conformity of image objects with features identified debris-covered glaciers as demonstrated in Figure 3.2. It is important to note that while one debris-covered glacier could be comprised of many image objects, the boundaries of those image objects generally correspond to the boundaries of debris-covered glaciers identifiable through visual interpretation. Although the agreement between image object boundaries and manually delineated DCG boundaries was good overall, there were some instances where they diverged, creating image objects with potential for mixed land-cover classes that could impact the accuracy of classification of DCGs. 


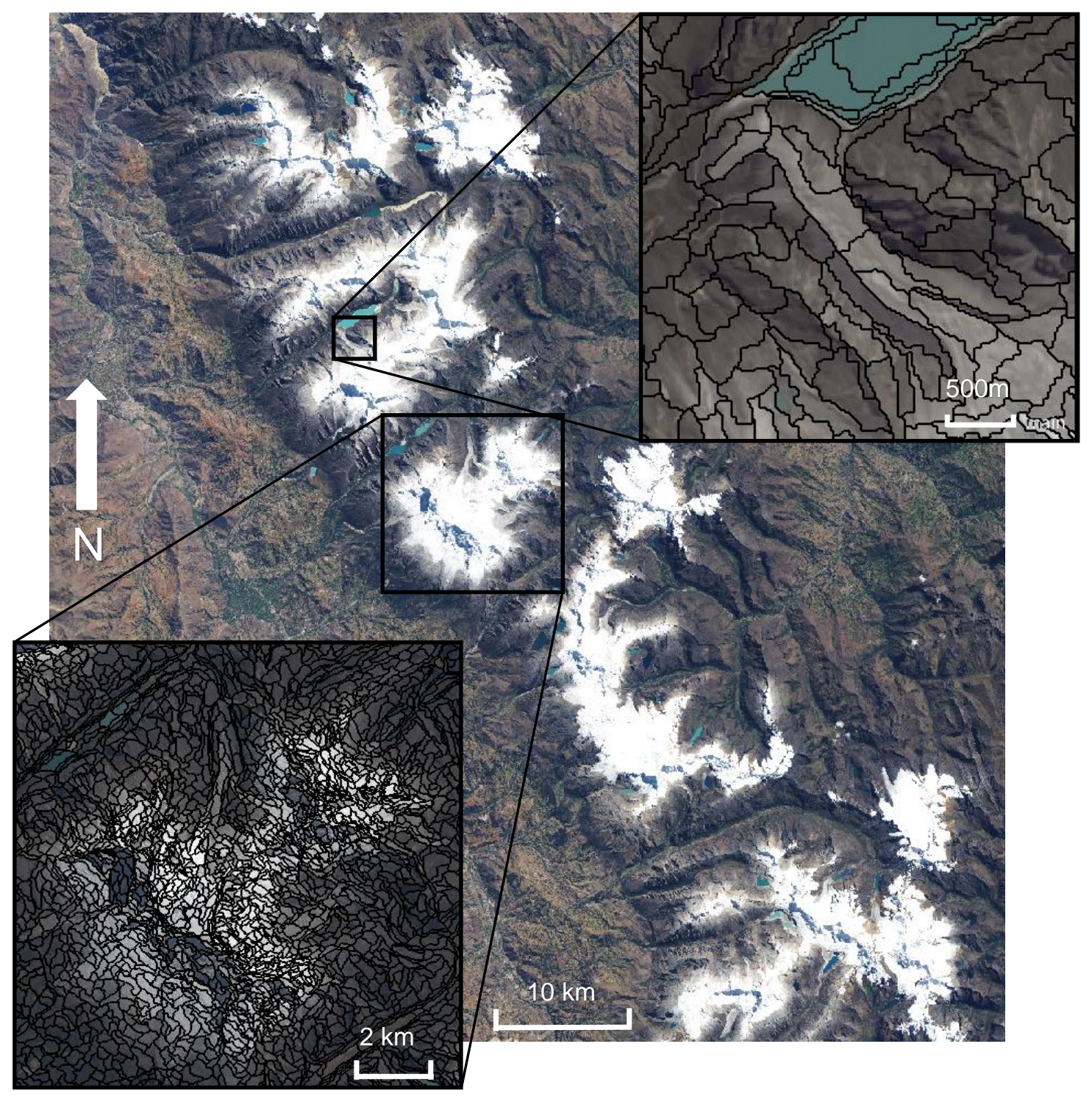

Figure 3.2 True color composite of Cordillera Blanca region showing final segmentation results. Two subsets displayed at different scales. Scale Parameter $=12$, Shape Parameter $=0.3$, Compactness Parameter $=0.2$. Landsat OLI (RGB: 4-3-2). 


\section{Initial Classification}

The initial classification of glacial ice resulted in an estimated $468.81 \mathrm{~km}^{2}$ of glacial ice in the study area, as compared with $486.4 \mathrm{~km}^{2}$ identified in the 2003 SPOT-based GLIMS polygons, and $456.5 \mathrm{~km}^{2}$ in the 2005 ASTER-based GLIMS data. Burns and Nolin (2014) also report a total glacier area (including debris-covered areas) of $482 \mathrm{~km}^{2}$ in 2010 . Area estimates for vegetation are not provided, as these areas comprise the majority of the Landsat tile, and are of no further interest for this study. An example of the results of initial classification are displayed in Figure 3.3.

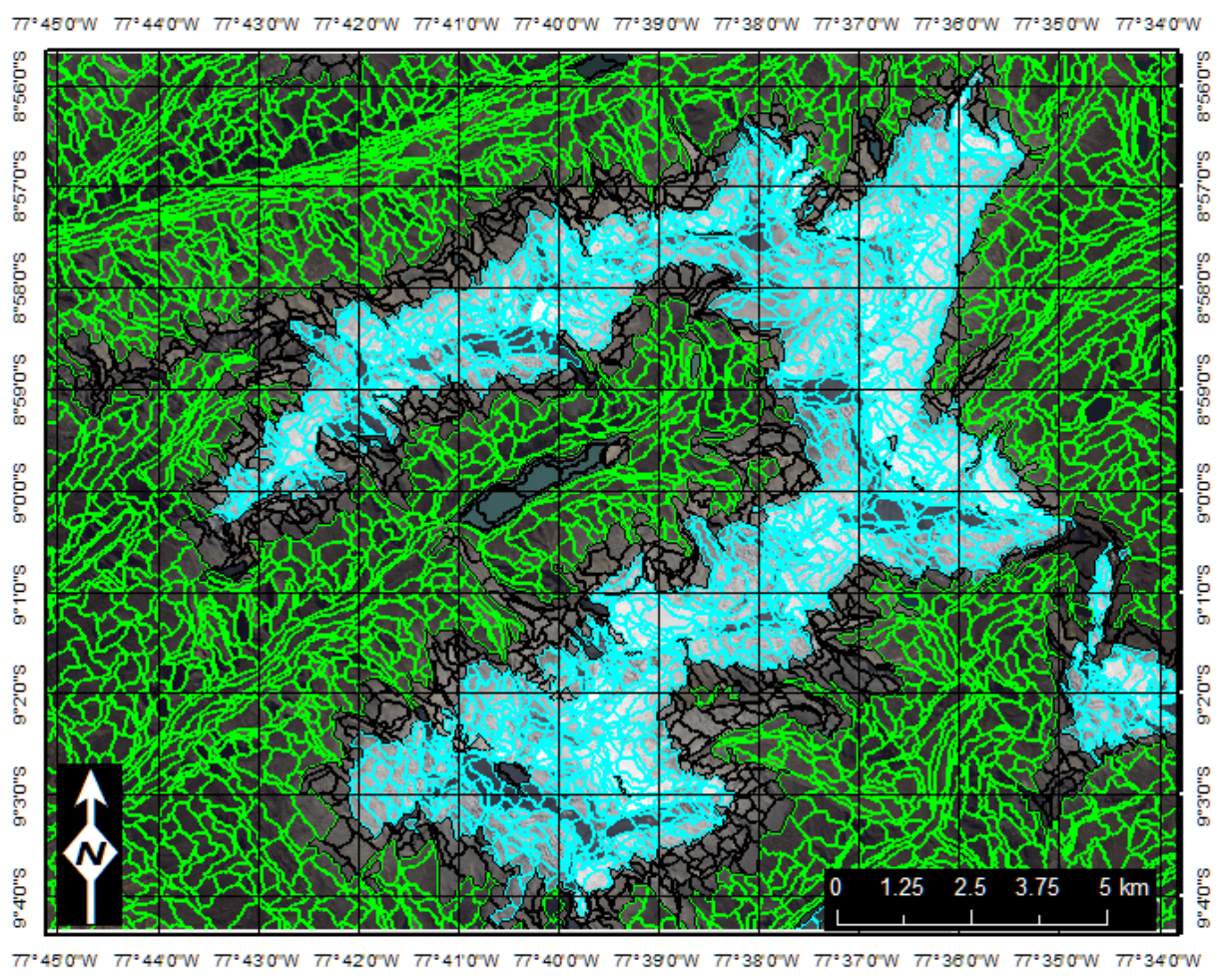

Figure 3.3 Results of initial classification. Subset of study area centered on Laguna Parón and Huandoy Massif. Green = vegetation; Cyan = glacier; Black = unclassified 


\section{Tree-Based Classifiers}

Initial classification of glacier ice and vegetation left 4,280 image objects remaining as unclassified. Of these objects 172 intersected the manually delineated DCG polygons, and were thus assigned to class DCG for use as training and validation data. The 172 image objects identified by intersection as DCG occupy a total area of $16.4 \mathrm{~km}^{2}$, which is consistent with the estimates from the reference data (Table 3.1).

A $70 \%$ random sample of the image object data with the 30 predictor variables was used to train the random forests and CTree classifiers. The resulting models were then applied to the full set of 4,280 image objects for validation. The random forests model classified 650 image objects as DCG, with a total area of $46.1 \mathrm{~km}^{2}$, and an OOB error rate of $13.3 \%$. Plotting the error rate against the number of trees used in the model demonstrates that 500 trees were sufficient to stabilize error (Figure 3.4).

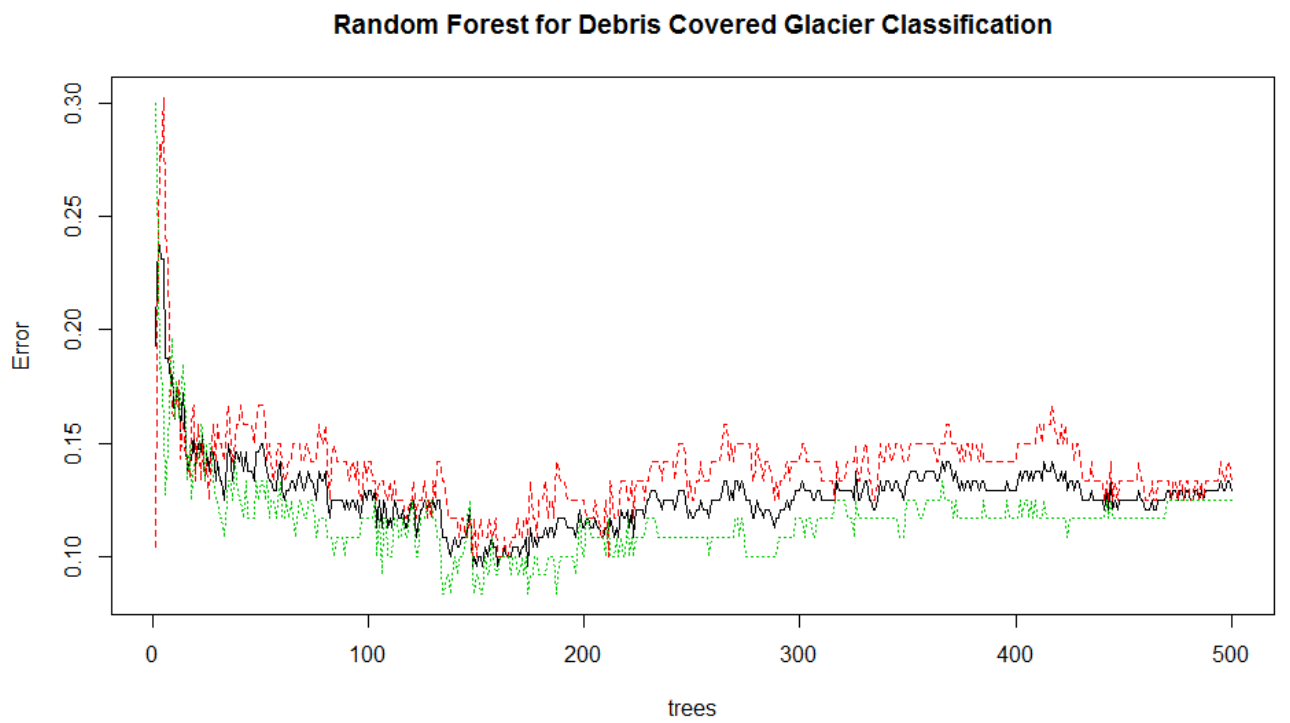

Figure 3.4 Out-of-bag error rate plot. OOB error plotted against the number of trees included in the model. The error rate stabilizes after 500 trees to the point where any variations are accounted for by statistical noise. 
The random forests algorithm provide a means for assessing the importance of individual predictor variables in the model. The variable importance plot (Figure 3.5) for the random forests model depicts the decrease in accuracy of the model (i.e. the percentage increase in OOB error rate) resulting from the permutation of each predictor variable. A greater decrease in accuracy indicates greater importance of the variable in question to the performance of the model.

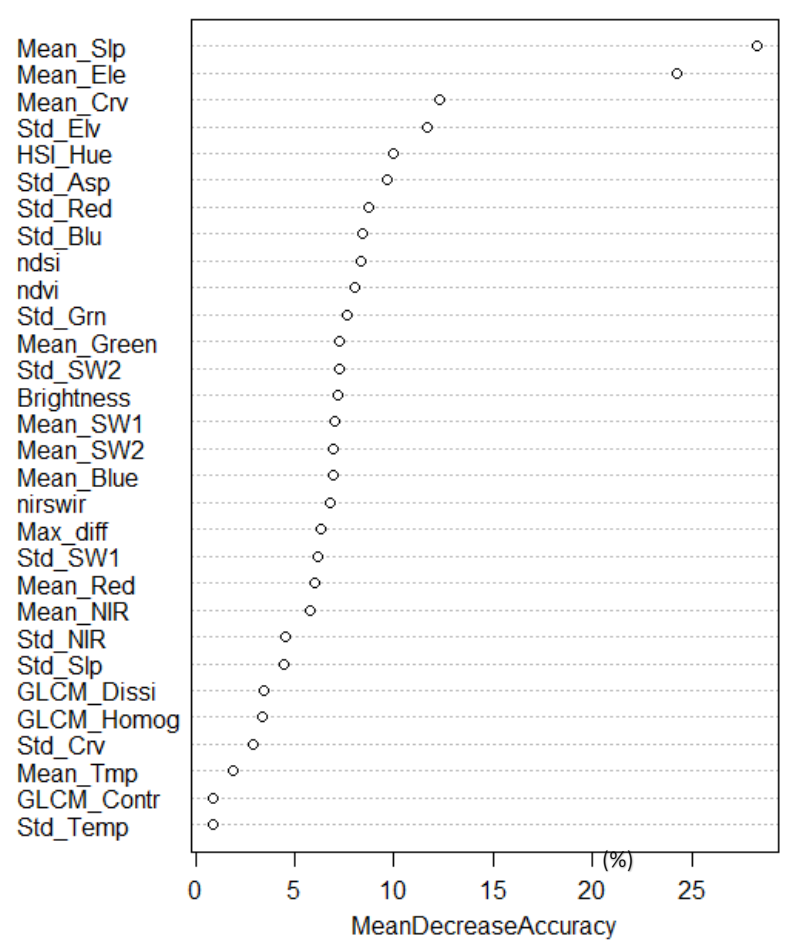

Figure 3.5 Variable importance plot for random forest model, showing the mean decrease in accuracy for each predictor variable. Mean decrease in accuracy corresponds to the percentage increase in the OOB error rate.

The variable importance plot in Figure 3.5 shows that terrain variables, including mean slope, mean elevation, mean curvature, and standard deviation of elevation contributed most to the random forests model's prediction of DCGs. Mean slope and mean elevation were the most important predictor variables, showing mean decrease in 
accuracy values of $29.3 \%$ and $25.7 \%$ respectively. Also of relatively high importance are the hue component of the HSI transformation, and the standard deviations of the red and blue bands. This suggests that the variability of spectral reflectance within image objects has a stronger influence on predictions of DCGs than does overall reflectivity in individual wavelength regions. Less informative, the textural features like GLCM Dissimilarity, Homogeneity, and Contrast have little importance in the predictive ability of the random forests classification.

The CTree model classified 897 objects as DCG, with a total area of $62.5 \mathrm{~km}^{2}$. CTree, as a single-tree classification, is unable to match the overall predictive performance of random forests. However, it does provide an enhanced level of interpretability through its resulting tree diagram (Figure 3.6).

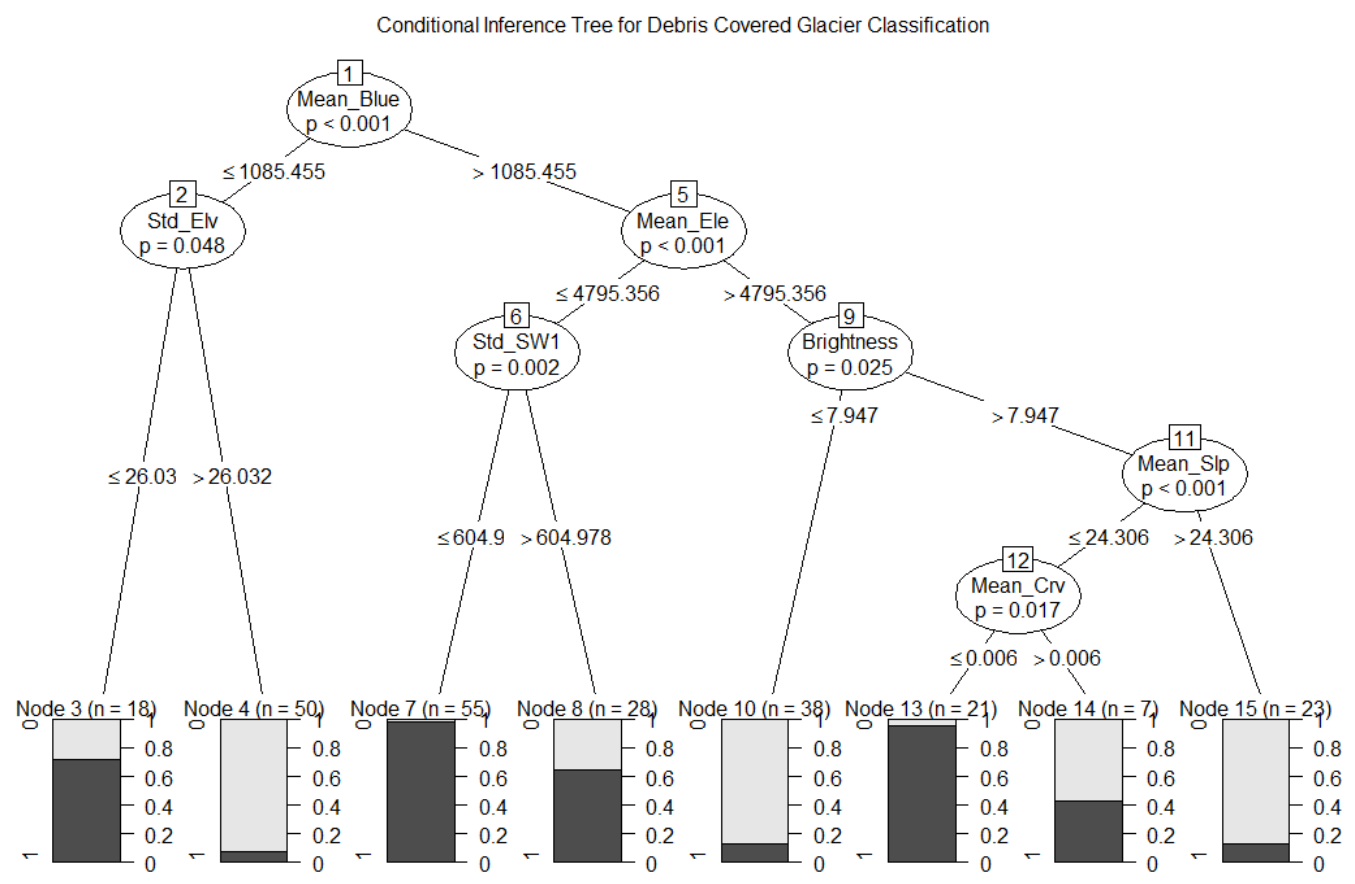

Figure 3.6 Tree diagram for conditional inference tree. Classification of DCG (1) vs non-DCG (0). 
The tree diagram depicts the split decisions used to classify the image objects into DCG or non-DCG. At each node in the tree a predictor variable is selected, and the cases are split into binary groups based on a critical value for that variable. Split decisions are then made recursively at each resulting node, and the process repeats until the splits fail to demonstrate statistical significance at the $95 \%$ confidence level. The results are a number of terminal nodes or "leaves" representing discrete groups of cases. At each terminal node, the number of cases and the fraction of those cases belonging to class DCG (1) or non-DCG (0) is given. The tree in Figure 3.6 would be very similar to a single tree in the random forests model, which combines the results of 500 trees for more robust performance.

While this CTree model does utilize some spectral features such as mean blue reflectance and standard deviation of shortwave reflectance, the overall low importance of those variables in the more robust random forests model suggests their appearance here may be more a result of the tendency for single tree models to overfit the data. In

general, the results of this single CTree model should be interpreted with some caution, as it represents but one possible tree. Re-fit one hundred times, the tree could yield different combinations of predictor variables, though the most important variables should reappear consistently.

\section{Classification Accuracy}

Error matrices for the random forests and CTree classifiers reveal more detail about the results of the models (Table 3.3 and Table 3.4, respectively). The random forests 
model achieved an overall accuracy of $88.5 \%$, while the CTree model achieved $81.6 \%$ overall accuracy. The Kappa statistic for the random forests was calculated as $K=0.36$ as compared with $K=0.21$ for CTree. Both values fall into the "fair" range for strength of agreement suggested by (Landis and Koch (1977)). The false positive rate for random forests was $11.8 \%$ at a sensitivity rate of $96.5 \%$, while for CTree the FPR was $18.4 \%$ at a sensitivity of $82.0 \%$.

Table 3.3 Error matrix for random forests model.

\begin{tabular}{|c|c|c|c|c|c|}
\hline & \multicolumn{2}{|c|}{ Reference } & \multirow[b]{2}{*}{ Totals } & \multirow[b]{2}{*}{ User's Accuracy } \\
\hline & & DCG_No & DCG_Yes & & \\
\hline \multirow{2}{*}{ 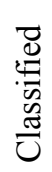 } & DCG_No & 3,624 & 6 & 3,630 & $99.8 \%$ \\
\hline & DCG_Yes & 484 & 166 & 650 & $25.5 \%$ \\
\hline & Totals & 4,108 & 172 & 4,280 & \\
\hline & $\begin{array}{l}\text { Producer's Accuracy/ } \\
\text { Sensitivity Rate }\end{array}$ & $88.2 \%$ & $96.5 \%$ & & Total: $88.5 \%$ \\
\hline & False Positive Rate & $11.8 \%$ & & & \\
\hline
\end{tabular}

Table 3.4 Error matrix for conditional inference tree model.

\begin{tabular}{|c|c|c|c|c|c|}
\hline & \multicolumn{2}{|c|}{ Reference } & \multirow[b]{2}{*}{ Totals } & \multirow[b]{2}{*}{ User's Accuracy } \\
\hline & & DCG_No & DCG Yes & & \\
\hline \multirow{5}{*}{ 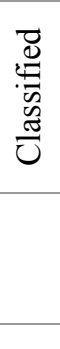 } & DCG_No & 3,352 & 31 & 3,383 & $99.08 \%$ \\
\hline & DCG_Yes & 756 & 141 & 897 & $15.7 \%$ \\
\hline & Totals & 4,108 & 172 & 4,280 & \\
\hline & $\begin{array}{l}\text { Producer's Accuracy/ } \\
\text { Sensitivity Rate }\end{array}$ & $81.6 \%$ & $82.0 \%$ & & Total: $81.6 \%$ \\
\hline & False Positive Rate & $18.4 \%$ & & & \\
\hline
\end{tabular}




\section{Spatial Analysis of Classification Results}

To better understand the patterns of errors associated with the random forests classification of DCGs, image objects were mapped according to RF predicted class membership values and overlaid with manually delineated reference data and Bing Maps $^{\mathrm{TM}}$ imagery (Figure 3.7). A visual analysis of the data was conducted with the intent to identify any obvious spatial components to the errors in the RF classification.

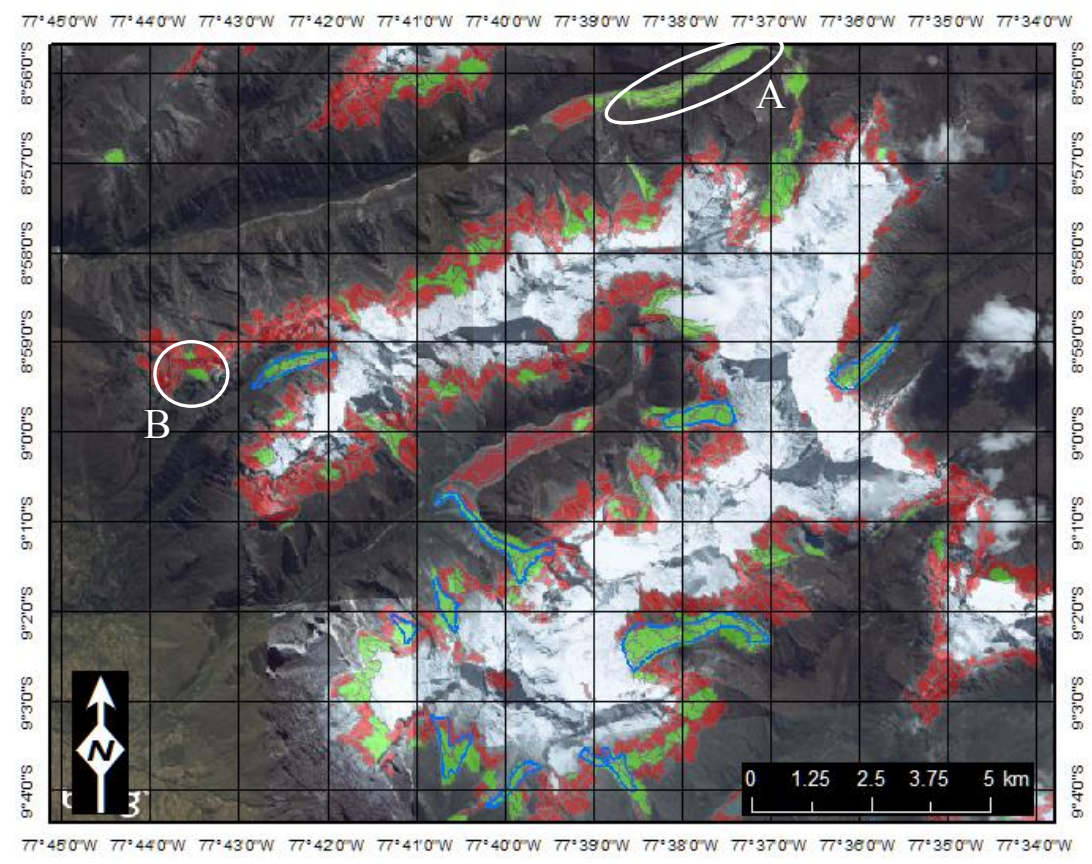

Figure 3.7 Spatial analysis of error for subset of study area. Random forest model class predictions $($ Green $=$ DCG, Red $=$ Non-DCG), overlaid with manual delineated reference data (blue). A. False positive - fluvial sediments. B. False positive - small isolated area.

With respect to Figure 3.7, areas that are illuminated in green were classified as DCG by the RF classifier. Classification errors occur wherever those areas occur independently of the manually delineated DCG boundaries (in blue). Visual interpretation of those areas show several patterns of misclassification that could be attenuated with additional spatial 
queries. One such example occurs in Figure 3.7 at location "A", where a valley floor comprised of fluvial sediments is erroneously identified as DCG. The slope, curvature and spectral signal of these sediment deposits is similar to that of a debris-covered glacier, but these sediments, across the study area, tend to occur at lower elevations than DCGs. By filtering the classified image polygons for areas below 4200m elevation, we can effectively remove these areas from consideration and improve the overall accuracy of DCG estimates.

Another common misclassification relates to very small image objects that are isolated from other DCG objects, and from glacier ice areas. This phenomenon is evidenced by location "B" in Figure 3.7. These image objects are small, not contiguous to other DCG objects, and not found in close proximity to glacier ice as is characteristic of debris-covered glaciers. Reviewing the reference data reveals that the smallest identified DCGs have areas of $>0.08 \mathrm{~km}^{2}$. Merging contiguous DCG image objects together into larger polygons allows for the calculation of the total areas of those composite regions. Filtering the resulting polygons for areas $<0.08 \mathrm{~km}^{2}$ excludes the image objects that are unlikely to represent DCGs based on their small size. Additionally filtering for polygons that are not adjacent to glacier ice eliminates those regions that are isolated from glaciers and also unlikely to represent DCGs. By applying the filters above to exclude lower lying objects $(<4200 \mathrm{~m})$, small image objects $\left(<0.08 \mathrm{~km}^{2}\right)$, and isolated objects (not within $100 \mathrm{~m}$ of glacier ice) the area estimate of total DCG in the study area falls by $10.8 \mathrm{~km}^{2}$ to $35.3 \mathrm{~km}^{2}$, still nearly double the area of the reference data (Table 3.1 ). 


\section{CHAPTER 4: DISCUSSION}

The object-based image analysis approach to semi-automated mapping of debriscovered glaciers was largely effective in achieving the goals set forth at the beginning of this project. OBIA multiresolution image segmentation was mostly successful in identifying DCG boundaries from Landsat OLI and SRTM slope data, as evidenced by the $86 \%$ agreement between area estimates of DCGs derived from manual delineation $\left(14.4 \mathrm{~km}^{2}\right)$ and image objects that intersect the manually delineated polygons $\left(16.4 \mathrm{~km}^{2}\right)$. The tree-based machine learning techniques achieved high classification accuracies, including an $88.5 \%$ overall classification accuracy using the random forest approach, and an $81.6 \%$ overall accuracy using the conditional inference tree approach. Thus, the random forest classification results meet the target for land cover classification accuracy of $85 \%$ suggested by the USGS, while the CTree model falls just short (Anderson 1976). The random forest model was superior in all measures of classification accuracy and is recommended here as the more suitable approach for classification, while CTree provides value in the enhanced interpretability of the predictor variables that both classifiers agree are important. Employing the two classifiers side-by-side provides a richer account of the overall phenomenon of DCGs in the Cordillera Blanca than either could provide alone. As one of the first and only studies to use these techniques for DCG mapping, these findings strongly suggest that OBIA and tree-based machine learning can make significant contributions to the understanding of DCGs and glacial environments in general if pursued to maturity. 
As promising as the results of this study are in regards to the potential of OBIA and tree-based classifiers, instances of misclassification of non-DCG objects as DCGs reinforce the notion that the task in question is not an easy one. Findings from this analysis support previous findings in the DCG mapping literature, namely that accurate automated mapping of DCGs is difficult without augmentation by manual editing (Alifu and Tateishi 2013, Paul, Huggel and Kääb 2004, Ghosh, Pandey and Nathawat 2014); that geomorphometric terrain data show promise when combined with optical data (Shukla, Arora and Gupta 2010, Paul, Huggel and Kääb 2004); and that thermal data are of limited utility where debris cover is thick, as in the Cordillera Blanca (Alifu and Tateishi 2013, Veettil 2012, Racoviteanu et al. 2008).

\section{Image Segmentation Accuracy}

The accurate classification of features of interest within the OBIA framework begins with the segmentation of image data that results in image objects that are internally homogenous and representative of the real world phenomena that is targeted for extraction (Blaschke, Lang and Hay 2008). While the boundaries of the image objects resulting from image segmentation (Figure 3.5) generally agree with the boundaries of DCGs identified by manual delineation, there were clearly instances where they diverge. The most common errors occur where image object boundaries overshoot the manually delineated boundaries, resulting in the inclusion of mixed land cover classes in image objects that should homogeneously represent DCGs. Thus, the image segmentation algorithm suffers some of the same ambiguity of DCG boundaries as does the human analyst when interpreting where DCGs end and surrounding land cover (i.e. lateral and 
terminal moraines) begins. Furthermore, while the human analyst can make inferences about where the boundary should be placed based on contextual information, the segmentation algorithm cannot. There are several limitations to the image segmentation process as parameterized in this study that may be consequential in terms of the algorithm's ability to correctly interpret DCG boundaries.

The first and most prominent limitation is the spatial resolution of the image data employed in segmentation. Landsat OLI data, even when pan-sharpened to 15-meter resolution, may simply lack the detail necessary to resolve fine gradations in the surface reflectance of DCGs versus surrounding land cover. The use of higher resolution image data such as Quickbird ( 2.5-meter VNIR) or IKONOS (1-meter pan-sharpened VNIR) may yield improved results over Landsat OLI data, but at higher cost and with increased processing and storage requirements. An ideal scenario would consist of image segmentation using very-high resolution image data, and subsequent analysis employing multispectral VNIR/SWIR/TIR data from moderate resolution sensors and ancillary data from other sources. This "best of both worlds" model could reap the benefits of the higher resolution data as it relates to image segmentation, while exploiting the broader gamut of available information for image classification.

Another issue of resolution and scale arises in relation to the slope data employed in segmentation. The original SRTM elevation data from which the slope data were derived have a resolution of 90 meters. Again, this relatively coarse data may not contain the detail necessary to accurately discriminate DCGs as distinct morphometric units. Racoviteanu et al. (2007) find that the 90m resolution SRTM data limited the data's utility in glaciological applications in the Nevado Coropuna area of the Peruvian Andes. 
ASTER GDEM2 data provide improved spatial resolution, but were deemed unsuitable due to significant data artifacts and accuracy issues $( \pm 61 \mathrm{~m}$ vertical accuracy and $200 \mathrm{~m}$ 300m elevation spikes according to Racoviteanu et al. (2007)). Research suggests that with additional processing to correct for these errors, the GDEM2 data may represent the best available solution and warrant further consideration in future studies (Buchroithner and Bolch 2007). Airborne LiDAR data present another option for high resolution DEM data, but their availability are limited in many areas, and data acquisition is expensive (Karimi et al. 2012, Abermann et al. 2010). In summary, the accuracy and resolution of presently available DEM data present a significant limitation on efforts to accurately segment images using terrain information in efforts to map DCGs.

\section{Tree-Based Classifiers}

Much of the literature on DCG mapping has focused on pixel-based semi-automated decision tree approaches that use various thresholds of key spectral or terrain features to extract DCGs from the data (Paul, Huggel and Kääb 2004, Veettil 2012, Buchroithner and Bolch 2007). These approaches have largely relied on a priori knowledge of the critical values upon which the image data are partitioned or employ some type of interactive selection of those critical values. Relatively little attention has been focused on the potential for machine learning tree-based classifiers to classify DCGs given an extensive set of image-based variables. The present study demonstrates that these techniques exhibit great potential in this regard. The primary evidence of this potential is the high overall classification accuracy $(88.5 \%)$ achieved by the random forest classification. Table 3.3 shows that while the random forest is guilty of significant errors 
of commission as evidenced by the low user's accuracy for DCGs, it performs well in correctly classifying the DCGs from the reference data, with only six errors of omission (producer's accuracy $=96.5 \%$ ). This suggests that the input data do contain the information necessary to achieve separability of DCGs and non-DCGs.

Machine learning techniques also provide a potential advantage over the knowledgebased decision trees commonly employed in the DCG mapping literature, in that limited a priori understanding of the characteristics of debris-covered glaciers is required for classification. Rather than the analyst selecting the critical values for a limited set of image variables for which the relevance to DCGs has been established, the random forest approach can consume a wide gamut of input variables and select those that are most essential.

While machine learning techniques have not been extensively explored in relation to mapping supraglacial debris, the closest comparison comes from Brenning (2009), which assesses the predictive performance of eleven different classifiers for detecting rock glaciers (similar to debris-covered glaciers) in the San Juan Mountains of Colorado. The author submits randomly generated points with covariates from DEM data and Landsat imagery to the classifiers which range from statistical techniques (e.g. logistic regression and linear discriminant techniques) to machine-learning techniques like random forests. Brenning finds that random forests attain an FPR of $\sim 10.5 \%$, with linear discriminant techniques and generalized additive models producing the lowest FPR of the eleven classifiers tested, at $\sim 8-9 \%$. With the significantly higher sensitivity rate achieved here (96.5\%), and a comparable FPR (11.8\%), the results of the present study suggests that the random forest algorithm compares very favorably to existing literature on machine 
learning techniques for supraglacial debris mapping. However, future studies should consider the use of the linear discriminant and other statistical techniques that Benning found superior to random forests.

Despite the encouraging comparison of the present results with the findings of existing studies, the significant errors of commission committed by the random forest model are still of concern and warrant closer consideration. Further visual examination of these false positives indicates that there may be another phenomenon at play underestimation of the total number and area of DCGs in the manually delineated reference dataset, as well as in the GLIMS data. Close visual analysis of Bing Maps ${ }^{\mathrm{TM}}$ imagery and "ground-truthing" using Google Earth ${ }^{\mathrm{TM}}$ perspective views suggests that while there are many legitimate errors of commission made by the random forests classification, there are also many "false positives" that actually portray the visual signature of debris-covered glacier, but are not represented in the manually delineated reference data nor the GLIMS data. Figure 4.1 provides an example of this situation. The areas bounded by the red polygons bordering the margins of the clean glacier ice show many of the features typical of debris-covered ice including hummocky terrain, presence of small pools of water, and lobate features. While it is impossible to confirm the presence of ice under the debris layer without field study, there is a strong possibility that this example and many like it represent debris-covered glaciers that were simply overlooked during previous visual inventories. A conservative estimate of the area of these potential DCGs identified by visual survey of the random forest predictions is $\sim 3.0 \mathrm{~km}^{2}$, a $17 \%$ to $21 \%$ increase in the total area of debris-covered glaciers identified in the study area. It is possible that glacier recession in the occurring in the area since the 
imagery used in the GLIMS inventory was acquired has driven land cover change resulting in these debris-covered glacier areas, which would explain their absence in that data. Whether by simple omission or by recent changes, the presence of these undocumented DCGs raise questions about the extent of knowledge about the debriscovered glaciers in the area and their associated glacial and periglacial dynamics.

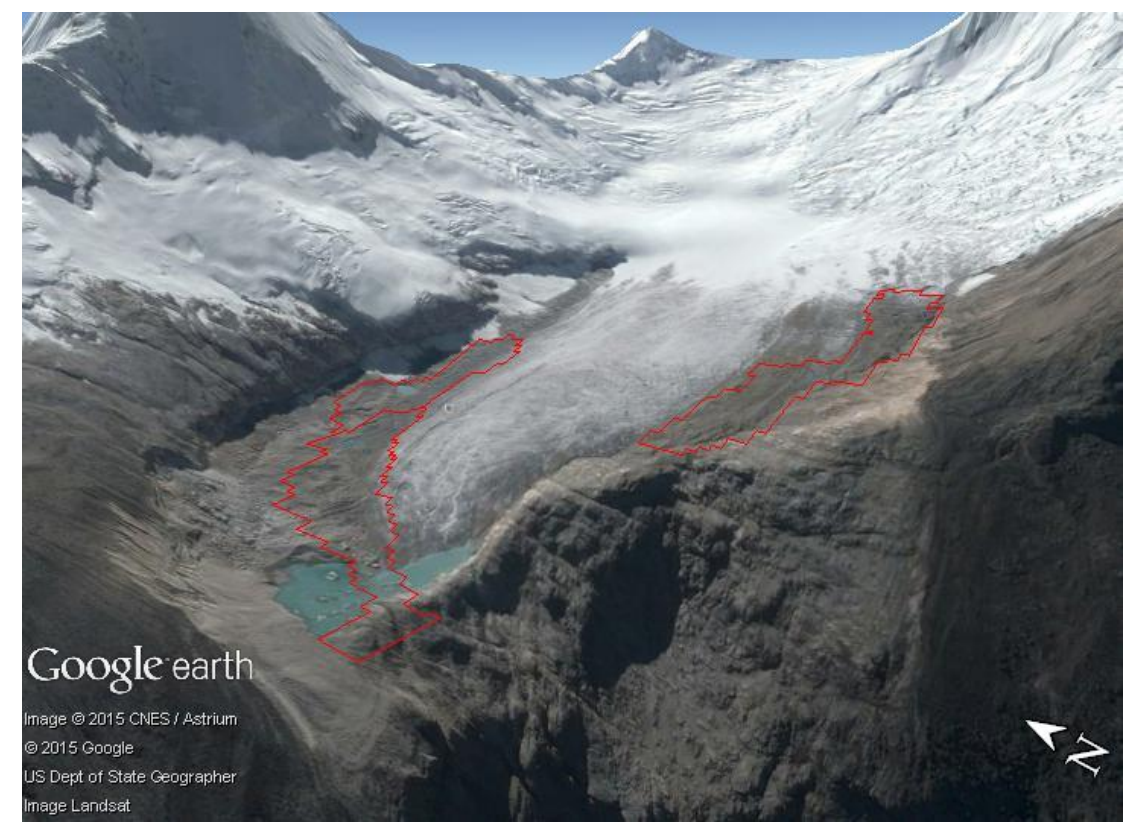

Figure 4.1 Potential debris-covered glaciers near the Artesonraju Glacier identified by random forest classification. Google Earth ${ }^{\mathrm{TM}}$ perspective showing potential debris-covered glaciers as red polygons. Image: 6/20/2015

There are several aspects of the classification procedure that warrant critical assessment in light of the classification results. The first relates to the simple geographic intersection method employed for identifying positive cases of DCG in the training data. Under this scheme, any image object that intersected a manually-delineated DCG polygon was assigned a positive value for DCG presence in the training data. A positive identification would result regardless of whether the image object in question was 
identical to a manually-derived DCG or if it shared only the smallest area. This inevitably resulted in some image objects that only slightly overlapped manually-delineated DCGs being included as positive cases in the training data. This is particularly concerning since these neighboring image objects likely represent the lateral and terminal moraines that often border DCGs and represent a principal source of confusion in their classification. This phenomenon likely accounts for some of the errors of commission during classification. An alternate approach could implement some manual correction of the training data after the initial intersection and before submitting to the classifiers.

Another decision that may hold implications for overall classification results and accuracy was the use of a $70 \%$ random sample of the training data to submit to the classifiers. It is an unusual case that a full reference dataset exists for the phenomenon that is to be classified, as is the case for this study, given the survey of the entire study area by manual delineation. Thus in this case there exists the luxury of selecting as much or as little training data for classification as is desired. In this instance a $70 \%$ sample was considered adequate, but further studies might choose to evaluate the accuracy of classifications conducted using a range of sample sizes. Identifying the optimal sample size to maximize classification accuracy while minimizing laborious manual delineation would be instructive for future efforts to classify DCGs in study areas where full manual survey would be impractical.

The hybrid nature of the approach to classification employed here is another element that may influence the outcomes of the classification. Because this study was not explicitly interested in quantifying land cover other than that of debris-covered glacier, it used the initial classification process to eliminate areas which could be identified as 
"non-DCG" with certainty. An alternative approach that could yield different classification results would employ training data for an exhaustive array of land cover classes found in the study area rather than a simple binary "DCG" versus "non-DCG" classification. This approach would forego initial classification of the area in favor of defining training data for class "glacier", class "water", class "vegetation", class "bedrock", class "moraine", etc. and letting the random forest model sort the image objects into the $n$ classes identified within the study area. This approach could potentially account for the notion that there could be multiple categories of "non-DCG" that may exhibit their own unique signatures given the covariates employed in the analysis. By enhancing the separability of the non-DCG objects into more homogenous groups, it is possible that image objects that were misclassified as DCG in the present study would fall into one of those groups.

\section{Characteristics of DCGs in the Cordillera Blanca}

One of the advantages that tree-based classifiers like random forests and conditional inference trees provide is the ability to interpret the importance of predictor variables to the resulting classification trees. The variable importance plot and associated mean decrease in accuracy statistics from the random forest model helps to rank predictor variables and determine the ones that are most vital to making accurate predictions. However, random forests lack the ability to interpret the critical values of those important predictor variables. On the other hand, while lacking in the predictive power of random forests, conditional inference trees provide an explicit representation of the predictor variables selected for classification and the critical values of those variables upon which 
binary split decisions have been made. In this study both classifiers have been employed to leverage their relative strengths and present a more complete picture of DCGs in the Cordillera Blanca.

As noted in the results, the random forest model relies heavily on terrain variables for predicting DCGs vs non-DCGs (Figure 3.5), suggesting that the clearest signature of DCGs in the study area is represented by morphometric characteristics. Indeed, when interpreting the tree diagram for the CTree model (Figure 3.6), the most striking feature is the correspondence of the CTree model's selection of terrain variables with that of the random forests model. The four top predictor variables (mean slope, mean elevation, mean curvature, and standard deviation of elevation) from the random forests model appear again here. Of additional interest are the critical values for these variables. Perhaps the clearest split occurs at node 2, where the standard deviation of elevation is selected and split at a value of $\sim 26 \mathrm{~m}$. Objects with values greater than $26 \mathrm{~m}$ are almost uniformly ( $\sim 90 \%$ ) classified a DCG, while objects with lower standard deviation of elevation values are more likely to be non-DCG. Interpreting this split decision, debriscovered glaciers are more likely represented by image objects with an elongate orientation along slope units with large differences in minimum and maximum elevation. This is consistent with the characteristic configuration of debris-covered glacier tongues that snake down-valley in long, narrow entities. Another interesting split occurs at node 11 , where the data were split on the mean slope of objects at a value of $\sim 24^{\circ}$. Objects with mean slopes less than $24^{\circ}$ had a high probability ( $\left.\sim 90 \%\right)$ of being classified as DCG, and vice versa. This is also consistent with the literature on debris-covered glaciers, which are typically lower in slope than surrounding terrain features (Ghosh, Pandey and 
Nathawat 2014, Paul, Huggel and Kääb 2004, Bandishoev, Dilo and Stein 2011). Indeed, Paul, Huggel and Kääb (2004) and Veettil (2012) find that a slope threshold of $<24^{\circ}$ is ideal for the delineation of DCGs in the Swiss Alps and the Karakoram, Himalaya respectively. Also of note is node 5 , where mean elevation is split at a value of $\sim 4800 \mathrm{~m}$. A greater portion of the $>4800 \mathrm{~m}$ objects are eventually classified as DCG, lending credibility to the elevation-based masking previously discussed in the results.

Of equal interest to the variables that ranked highest in importance are those that fell low in the rankings. The textural variables - GLCM, dissimilarity, homogeneity and contrast - were all ranked in the bottom six of the variable importance plot (Figure 3.5), with mean decrease in accuracy values all below 5\%. This result was unanticipated given the utility of textural analysis demonstrated by Racoviteanu and Williams (2012) for mapping DCGs in the Himalaya. However, a possible explanation for the insignificance of these variables may relate to the way the textural features were calculated within eCognition. Rather than generating textural features for individual spectral bands, these features were calculated using all data available within the image objects, including the terrain variables and thermal data. Racoviteanu and Williams (2012) apply the GLCM texture measures only to VNIR and SWIR data. Limiting the input bands for textural features to the optical bands of Landsat OLI may yield different results.

Also falling near the bottom of the variable importance plot as the third least important variable, is mean temperature, with a mean decrease in accuracy value of $<3 \%$. This was perhaps the most surprising outcome of the classification results, given the abundance of recent research that effectively utilize thermal infrared data for mapping DCGs (Alifu, Tateishi and Johnson 2015, Karimi et al. 2012, Bhardwaj et al. 2015, 
Shukla and Ali 2016). There are two possible explanations for the lack of a clear thermal signature for DCGs in the Cordillera Blanca as it relates to this study. The first is that the thickness of the debris layer on DCGs in the Cordillera Blanca exceeds the $40 \mathrm{~cm}-50 \mathrm{~cm}$ depth of debris, above which the cooling effect of underlying ice is not manifest on the debris surface (Taschner and Ranzi 2002, Ranzi et al. 2004). While there were no data available that comprehensively quantify debris depths in this region, a recent survey of the well-documented Jatunraju glacier found debris depths of several meters in the thickest parts, and over one meter in thinner portions (Emmer et al. 2015). It seems plausible that the debris layers of DCGs in the Cordillera Blanca are simply too thick for any thermal effect from underlying ice to be detectable on the surface.

Another possible explanation for the insignificance of the Landsat thermal IR data in this research relates to the data itself. The acquisition time of the Landsat OLI scene was 15:16 Zulu time, or about 9:16AM local time in the study area. The low solar elevation $\left(\sim 48^{\circ}\right)$ at this time of day resulted in deep topographic shadowing on many southerly and westerly facing slopes. On illuminated slopes there was a pronounced solar heating effect, while shaded slopes were generally cooler. This effect could be enough to obscure any clear thermal signatures exhibited by debris-covered glaciers. Techniques have been proposed to account for this illumination effect, and may be of utility for future studies employing this Landsat OLI data (Shukla, Arora and Gupta 2010). Nighttime imagery from the Landsat sensor and others may also be useful to overcome this challenge. Another potential concern is the 120 meter original resolution of Landsat OLI thermal data, which may be too coarse for effective discrimination of thermal anomalies associated with debris-covered glaciers. 


\section{The Context of Automated DCG Mapping}

Throughout the research process some common themes emerged in context to the larger body of literature that has been published concerning the automated mapping of debris-covered glaciers. Firstly, a large majority of this research has been concentrated on study areas in the Himalaya region and the European Alps. This focus in no doubt driven by the tight interconnections of glacial and periglacial dynamics, glacial hazards, and significant human populations found in these regions. However, relatively little attention has been focused on other regions with large concentrations of DCGS, such as the Cordillera Blanca, Alaska, and the Caucasus Mountains of Russia. This seems like a missed opportunity to evaluate and refine the techniques developed in the Himalaya and Alps to be more generalizable across geographic regions, and to advance general understanding of debris-covered glaciers and the glacial environments in which they are found. The present study evaluates a robust OBIA and machine learning technique in a region that has been understudied in the DCG mapping literature. The ability of the treebased machine learning classifiers to consume a large array of input variables with minimal a priori knowledge of their importance suggests that it may be well-suited for use in other areas where the unique character of DCGs is not well understood. It is recommended that future studies apply such techniques developed for automated mapping of DCGs to case studies from a multitude of regions where DCGs are prevalent in order to more thoroughly measure their efficacy.

Another theme that emerged from the research relates to the scale at which techniques for automated mapping of DCGs are developed and evaluated. Often researchers will identify a region such as the Himalaya or the European Alps where DCGs are 
concentrated, but then select case studies within those regions that are centered about a single glacier system or massif with the assumption that the case study could be representative of the larger region or even DCGs worldwide (Ranzi et al. 2004, Paul, Huggel and Kääb 2004, Bolch et al. 2007, Alifu, Tateishi and Johnson 2015). Mapping techniques are developed for that case study, but are rarely applied to the larger region. Given the variability of debris-covered glaciers observed in the Cordillera Blanca during this study, it follows that more regional scale inventories of DCGs that apply the automated techniques proposed in the existing literature are warranted. Regional scale research such as the present study would more fully expose the limitations of techniques that were parameterized for small study areas, and provide more accurate error estimates that could inform future analyses.

The third theme that developed from this study addresses the inconsistencies in the reporting of classification accuracies across the body of research that has been published on automated mapping of DCGs. In many cases, the present study included, accuracy is measured by reporting the difference in area calculations for DCGs derived from automated techniques versus a reference dataset (Bolch et al. 2007, Alifu, Tateishi and Johnson 2015) or visual correspondence of automated mapping versus reference data (Paul, Huggel and Kääb 2004). Some studies use traditional error matrix accuracy assessments, but as has been noted, they have shortcomings in relation to features that occupy small areas within a study area (Brenning 2009). It is difficult to make comparisons of the efficacy of various models for automated DCG mapping when the metrics by which they are measured are not consistent. This study elected to present classification results in multiple formats (error matrix, false positive rate, area estimates) 
in effort to facilitate evaluation against existing techniques. Ideally, a standard method for error reporting could be established and employed by future studies in effort to benchmark new and existing techniques for automated DCG mapping. 


\section{CHAPTER 5: CONCLUSIONS}

This research evaluated the efficacy of object-based image analysis and tree-based machine learning techniques with regard to their potential for automated extraction of debris-covered glaciers in the Cordillera Blanca region of Peru. Results demonstrated that OBIA is indeed capable of discriminating debris-covered glaciers using multiresolution image segmentation, and that tree-based classifiers, specifically the random forests model, can be successful in classifying debris-covered glaciers from optical imagery and terrain data, herein producing overall classification accuracy of $88.5 \%$ and a low false positive rate of $11.8 \%$. This study also demonstrates that automated classification of debris-covered glaciers is feasible in the Cordillera Blanca region where previous attempts were found to be unsuccessful (Burns and Nolin 2014). Moreover, the techniques presented here hold great promise of transferability to other regions with high concentrations of debris-covered glaciers, grounded in the ability of the random forests model to analyze large arrays of predictor variables. The current paradigm in automated mapping of DCGs necessitates a high degree of a priori knowledge of the specific characteristics of the study area, whereas the random forest approach can leverage the advantages of machine learning to efficiently partition the data without this expert knowledge.

The results of this study also revealed that previous efforts to inventory debris covered glaciers in the Cordillera Blanca may have underestimated debris-covered ice 
areas by as much as $20 \%$. The OBIA and machine learning techniques introduced in this thesis identified more than $3 \mathrm{~km}^{2}$ of potential debris-covered glacier in the Cordillera Blanca range that is not reflected in the benchmark GLIMS database. Future field-based assessments of the debris-covered glaciers in the Cordillera Blanca should include ground-truthing of these areas to definitively identify them as debris-covered glacier or other land cover. In an environment that is rapidly being altered in response to climate change, a thorough knowledge of the dynamics of these previously undocumented debriscovered glaciers areas is essential to understanding the larger picture of climate change responses of tropical glaciers. Moreover, at the local level these potential debris-covered glaciers could impact resident populations through the associated rapid growth of supraglacial and moraine-dammed lakes and other glacial hazards.

While this research has delivered answers for many of the questions raised at its outset, it also raises many more to be considered as future research directions are identified. The techniques presented demonstrated their effectiveness using freelyavailable moderate resolution Landsat OLI and SRTM data. However, the increasing accessibility of high resolution VNIR image data and better quality digital terrain data hold the promise of improved image segmentation and classification from OBIA methods. More consideration of the utility of thermal data and textural features in relation to these methods is also recommended, given their apparent success in other DCG mapping efforts. Also, the tree-based classifiers explored herein are but two of the many machine learning techniques extant, and though they are effective here other research show that a full survey of methods, including machine learning, linear discriminant 
techniques, and support vector machines is warranted for classification of debris-covered glaciers.

Finally, as glacial environments continue to come into sharper focus at the center of debates on global climate change, some consensus should be sought with regard to the direction and goals of the body of research pertaining to mapping debris-covered glaciers using remote sensing techniques. The scope and magnitude of the impact of this research could be increased by making positive changes in several facets, namely by: adopting standards for presenting research findings particularly with regard to accuracy reporting; objectively evaluating existing and new methodologies against one another and across geographic regions; moving beyond methodological case studies and conducting broader scale inventories of DCGs regionally and worldwide; and focusing more attention on unstudied and understudied regions with high concentrations of DCGs, such as the Cordillera Blanca. 


\section{REFERENCES}

Abermann, J., A. Fischer, A. Lambrecht \& T. Geist. 2010. On the potential of very highresolution repeat DEMs in glacial and periglacial environments. The Cryosphere, 4, 53-65.

Albregtsen, F. 2008. Statistical texture measures computed from gray level coocurrence matrices. Image processing laboratory, department of informatics, university of oslo, 1-14.

Alifu, H. \& R. Tateishi. 2013. Mapping of debris-covered glacier using combination of Landsat band ratio imagery and digital elevation model. In The conference of The Remote Sensing Society of Japan.

Alifu, H., R. Tateishi \& B. Johnson. 2015. A new band ratio technique for mapping debris-covered glaciers using Landsat imagery and a digital elevation model. International Journal of Remote Sensing, 36, 2063-2075.

Anderson, J. R. 1976. A land use and land cover classification system for use with remote sensor data. US Government Printing Office.

Aniya, M., H. Sato, R. Naruse, P. Skvarca \& G. Casassa. 1996. The use of satellite and airborne imagery to inventory outlet glaciers of the Southern Patagonia Icefield, South America. Photogrammetric Engineering and Remote Sensing, 62, 13611369.

Baatz, M. \& A. Schäpe. 2000. Multiresolution segmentation - an optimization approach for high quality multi-scale segmentation. In Angewandte Geographische Informations-Verarbeitung XI, eds. J. Strobl, T. Blaschke \& G. Griesebner, 12-23. Karlsruhe: Wichmann Verlag.

Bandishoev, M., A. Dilo \& A. Stein. 2011. Assessing the debris around glaciers using remote sensing and random sets. In 7th International Symposium on Spatial Data Quality, 27-32. Coimbra, Portugal: INESC Coimbra. 
Baraer, M., B. G. Mark, J. M. McKenzie, T. Condom, J. Bury, K.-I. Huh, C. Portocarrero, J. Gómez \& S. Rathay. 2012. Glacier recession and water resources in Peru's Cordillera Blanca. Journal of Glaciology, 58, 134-150.

Benn, D., T. Bolch, K. Hands, J. Gulley, A. Luckman, L. Nicholson, D. Quincey, S. Thompson, R. Toumi \& S. Wiseman. 2012. Response of debris-covered glaciers in the Mount Everest region to recent warming, and implications for outburst flood hazards. Earth-Science Reviews, 114, 156-174.

Benn, D. I. \& D. J. A. Evans. 2010. Glaciers and Glaciation. Hodder Education.

Benn, D. I., M. P. Kirkbride, L. A. Owen \& V. Brazier. 2003. Glaciated valley landsystems. Glacial Landsystems. Arnold, London, 372-406.

Benz, U. C., P. Hofmann, G. Willhauck, I. Lingenfelder \& M. Heynen. 2004. Multiresolution, object-oriented fuzzy analysis of remote sensing data for GIS-ready information. ISPRS Journal of photogrammetry and remote sensing, 58, 239-258.

Berger, C., M. Voltersen, S. Hese, I. Walde \& C. Schmullius. 2013. Robust extraction of urban land cover information from HSR multi-spectral and LiDAR data. Selected Topics in Applied Earth Observations and Remote Sensing, IEEE Journal of, 6, 2196-2211.

Bhardwaj, A., P. Joshi, L. Sam, M. K. Singh, S. Singh \& R. Kumar. 2015. Applicability of Landsat 8 data for characterizing glacier facies and supraglacial debris.

International Journal of Applied Earth Observation and Geoinformation, 38, 5164.

Binaghi, E., P. Madella, M. G. Montesano \& A. Rampini. 1997. Fuzzy contextual classification of multisource remote sensing images. Geoscience and Remote Sensing, IEEE Transactions on, 35, 326-340.

Bishop, M. P., J. A. Olsenholler, J. F. Shroder, R. G. Barry, B. H. Raup, A. B. G. Bush, L. Copland, J. L. Dwyer, A. G. Fountain, W. Haeberli, A. Kääb, F. Paul, D. K. Hall, J. S. Kargel, B. F. Molnia, D. C. Trabant \& R. Wessels. 2004. Global Land Ice Measurements from Space (GLIMS): Remote Sensing and GIS Investigations of the Earth's Cryosphere. Geocarto International, 19, 57-84.

Blaschke, T., S. Lang \& G. Hay. 2008. Object-Based Image Analysis: Spatial Concepts for Knowledge-Driven Remote Sensing Applications. Springer. 
Blaschke, T., S. Lang, E. Lorup, J. Strobl \& P. Zeil. 2000. Object-oriented image processing in an integrated GIS/remote sensing environment and perspectives for environmental applications. Environmental information for planning, politics and the public, 2, 555-570.

Bolch, T., M. F. Buchroithner, A. Kunert \& U. Kamp. 2007. Automated delineation of debris-covered glaciers based on ASTER data. In Geoinformation in Europe. proceedings of the 27th EARSeL Symposium, 4-6.

Breiman, L. 2001. Random forests. Machine learning, 45, 5-32.

Brenning, A. 2009. Benchmarking classifiers to optimally integrate terrain analysis and multispectral remote sensing in automatic rock glacier detection. Remote Sensing of Environment, 113, 239-247.

Brock, B. W., C. Mihalcea, M. P. Kirkbride, G. Diolaiuti, M. E. J. Cutler \& C. Smiraglia. 2010. Meteorology and surface energy fluxes in the 2005-2007 ablation seasons at the Miage debris-covered glacier, Mont Blanc Massif, Italian Alps. Journal of Geophysical Research: Atmospheres, 115, n/a-n/a.

Buchroithner, M. F. \& T. Bolch. 2007. An automated method to delineate the ice extension of the debris-covered glaciers at Mt. Everest based on ASTER imagery. In Grazer Schriften der Geographie und Raumforschung 43, 71-78. Graz, Austria: na.

Burns, P. \& A. Nolin. 2014. Using atmospherically-corrected Landsat imagery to measure glacier area change in the Cordillera Blanca, Peru from 1987 to 2010. Remote Sensing of Environment, 140, 165-178.

Carey, M. P. 2010. In the shadow of melting glaciers: climate change and Andean society. Oxford University Press.

Congalton, R. G. 1991. A review of assessing the accuracy of classifications of remotely sensed data. Remote sensing of environment, 37, 35-46.

Dansgaard, W., S. Johnsen, H. Clausen, D. Dahl-Jensen, N. Gundestrup, C. Hammer, C. Hvidberg, J. Steffensen, A. Sveinbjörnsdottir \& J. Jouzel. 1993. Evidence for general instability of past climate from a 250-kyr ice-core record. Nature, 364, 218-220. 
Dozier, J. 1989. Spectral signature of alpine snow cover from the landsat thematic mapper. Remote Sensing of Environment, 28, 9-22.

Dupuy, S., G. Lainé \& T. Tormos. 2012. OBIA for combining LiDAR and multispectral data to characterize forested areas and land cover in a tropical region. In 4th International Conference on Geographic Object-Based Image Analysis (GEOBIA), $7 \mathrm{p}$.

Emmer, A., E. C. Loarte, J. Klimeš \& V. Vilímek. 2015. Recent evolution and degradation of the bent Jatunraju glacier (Cordillera Blanca, Peru). Geomorphology, 228, 345-355.

ESRI. 2014. ArcGIS Desktop v10.2.2. Redlands, CA.: Environmental Systems Research Institute.

Felde, G. W., G. P. Anderson, T. W. Cooley, M. W. Matthew, S. M. Adler-Golden, A. Berk \& J. Lee. 2003. Analysis of Hyperion data with the FLAASH atmospheric correction algorithm. In Geoscience and Remote Sensing Symposium, 2003. IGARSS'03. Proceedings. 2003 IEEE International, 90-92. IEEE.

Ghimire, B., J. Rogan, V. R. Galiano, P. Panday \& N. Neeti. 2012. An Evaluation of Bagging, Boosting, and Random Forests for Land-Cover Classification in Cape Cod, Massachusetts, USA. GIScience \& Remote Sensing, 49, 623-643.

Ghosh, S., A. C. Pandey \& M. S. Nathawat. 2014. Mapping of debris-covered glaciers in parts of the Greater Himalaya Range, Ladakh, western Himalaya, using remote sensing and GIS. Journal of Applied Remote Sensing, 8, 083579-083579.

Google Earth. Google.

Hall, D. K., G. A. Riggs \& V. V. Salomonson. 1995. Development of methods for mapping global snow cover using moderate resolution imaging spectroradiometer data. Remote Sensing of Environment, 54, 127-140.

Hambrey, M. 1994. Glacial Environments. Taylor \& Francis.

Hand, D. J. 1997. Construction and Assessment of Classification Rules. Wiley. 
Hansen, M., R. Dubayah \& R. DeFries. 1996. Classification trees: an alternative to traditional land cover classifiers. International journal of remote sensing, 17, 1075-1081.

Haralick, R. M., K. Shanmugam \& I. H. Dinstein. 1973. Textural features for image classification. Systems, Man and Cybernetics, IEEE Transactions on, 610-621.

Hendriks, J. \& P. Pellikka. 2007. Semi-automatic glacier delineation from Landsat imagery over Hintereisferner in the Austrian Alps. Zeitschrift fur Gletscherkunde und Glazialgeologie, 41, 55.

Horning, N. 2010. Random Forests: An algorithm for image classification and generation of continuous fields data sets. In Proceeding of International Conference on Geoinformatics for Spatial Infrastructure Development in Earth and Allied Sciences, 9-11.

Hothorn, T., K. Hornik, C. Strobl, A. Zeileis \& M. T. Hothorn. 2015. Package 'party'. Package Reference Manual for Party Version 0.9-998, 16, 37.

Hothorn, T., K. Hornik \& A. Zeileis. 2006. Unbiased recursive partitioning: A conditional inference framework. Journal of Computational and Graphical Statistics, 15, 651-674.

Huggel, C., A. Kääb, W. Haeberli, P. Teysseire \& F. Paul. 2002. Remote sensing based assessment of hazards from glacier lake outbursts: a case study in the Swiss Alps. . Canadian Geotechnical Journal., 39, 316-330.

IPCC. 2013. Climate Change 2013: The Physical Science Basis. Contribution of Working Group I to the Fifth Assessment Report of the Intergovernmental Panel on Climate Change. Cambridge, United Kingdom and New York, NY, USA: Cambridge University Press.

Ishwaran, H. \& J. S. Rao. 2009. Decision Trees: Introduction. In Encyclopedia of Medical Decision Making, 323-328. Thousand Oaks, CA: SAGE Publications, Inc.

Jarvis, A., H. I. Reuter, A. Nelson \& E. Guevara. 2008. Hole-filled SRTM for the globe Version 4, available from the CGIAR-CSI SRTM 90m Database. 
Jensen, J. R. 2007. Remote Sensing of the Environment: An Earth Resource Perspective. Pearson Prentice Hall.

Johnson, A. M. 1976. The Climate of Peru, Bolivia and Ecuador. In World survey of climatology, ed. W. Schwerdtfeger, 71. Amsterdam, etc.: Elsevier.

Kääb, A., C. Huggel, F. Paul, R. Wessels, B. Raup, H. Kieffer \& J. Kargel. 2002. Glacier monitoring from ASTER imagery: accuracy and applications. In Proceedings of EARSeL-LISSIG-Workshop Observing our Cryosphere from Space, 43-53. Citeseer.

Karimi, N., A. Farokhnia, L. Karimi, M. Eftekhari \& H. Ghalkhani. 2012. Combining optical and thermal remote sensing data for mapping debris-covered glaciers (Alamkouh Glaciers, Iran). Cold Regions Science and Technology, 71, 73-83.

Kaser, G. \& H. Osmaston. 2002. Tropical glaciers. Cambridge ; New York: Cambridge University Press.

Kirkbride, M. P. 2011. Debris-Covered Glaciers. In Encyclopedia of Snow, Ice and Glaciers, eds. M. P. Bishop, V. P. Singh, H. Björnsson, P. Singh, U. K. Haritashya, W. Haeberli, J. Oerlemans, J. F. Shroder \& M. Tranter, 190-192. Springer.

Klein, A. G. \& B. L. Isacks. 1999. Spectral mixture analysis of Landsat thematic mapper images applied to the detection of the transient snowline on tropical Andean glaciers. Global and Planetary Change, 22, 139-154.

König, M., J. G. Winther \& E. Isaksson. 2001. Measuring snow and glacier ice properties from satellite. Reviews of Geophysics, 39, 1-27.

Laben, C. A. \& B. V. Brower. 2000. Process for enhancing the spatial resolution of multispectral imagery using pan-sharpening. Google Patents.

Landis, J. R. \& G. G. Koch. 1977. The measurement of observer agreement for categorical data. Biometrics, 33, 159-174.

Li, Z., W. Sun \& Q. Zeng. 1998. Measurements of glacier variation in the Tibetan Plateau using Landsat data. Remote Sensing of Environment, 63, 258-264. 
Liaw, A. \& M. Wiener. 2002. Classification and regression by randomForest. $R$ news, 2 , $18-22$.

Loibl, D., F. Lehmkuhl \& J. Grießinger. 2014. Reconstructing glacier retreat since the Little Ice Age in SE Tibet by glacier mapping and equilibrium line altitude calculation. Geomorphology, 214, 22-39.

Mark, B. \& G. O. Seltzer. 2003. Tropical glacier meltwater contribution to stream discharge: a case study in the Cordillera Blanca, Peru. Journal of Glaciology, 49, 271-281.

Meinel, G. \& M. Neubert. 2004. A comparison of segmentation programs for high resolution remote sensing data. International Archives of Photogrammetry and Remote Sensing, 35, 1097-1105.

Nakawo, M. \& B. Rana. 1999. Estimate of Ablation Rate of Glacier Ice under a Supraglacial Debris Layer. Geografiska Annaler: Series A, Physical Geography, 81, 695-701.

NSIDC. 2015a. Facts about Glaciers. Boulder, CO: National Snow and Ice Data Center.

NSIDC. 2015b. GLIMS Glacier Database. Boulder, CO: National Snow and Ice Data Center.

Paul, F., N. Barrand, S. Baumann, E. Berthier, T. Bolch, K. Casey, H. Frey, S. Joshi, V. Konovalov \& R. L. Bris. 2013. On the accuracy of glacier outlines derived from remote-sensing data. Annals of Glaciology, 54, 171-182.

Paul, F., C. Huggel \& A. Kääb. 2004. Combining satellite multispectral image data and a digital elevation model for mapping debris-covered glaciers. Remote Sensing of Environment, 89, 510-518.

Paul, F., C. Huggel, A. Kääb, T. Kellenberger \& M. Maisch. 2002a. Comparison of TMderived glacier areas with higher resolution data sets.

Paul, F. \& A. Kääb. 2005. Perspectives on the production of a glacier inventory from multispectral satellite data in Arctic Canada: Cumberland Peninsula, Baffin Island. Annals of Glaciology, 42, 59-66. 
Paul, F., A. Kääb, M. Maisch, T. Kellenberger \& W. Haeberli. 2002b. The new remotesensing-derived Swiss glacier inventory: I. Methods. Annals of Glaciology, 34, 355-361.

Pellikka, P. \& W. G. Rees. 2009. Remote Sensing of Glaciers: Techniques for Topographic, Spatial and Thematic Mapping of Glaciers. Taylor \& Francis.

Petit, J. R., J. Jouzel, D. Raynaud, N. I. Barkov, J.-M. Barnola, I. Basile, M. Bender, J. Chappellaz, M. Davis \& G. Delaygue. 1999. Climate and atmospheric history of the past 420,000 years from the Vostok ice core, Antarctica. Nature, 399, 429436.

Quincey, D., R. Lucas, S. Richardson, N. Glasser, M. Hambrey \& J. Reynolds. 2005. Optical remote sensing techniques in high-mountain environments: application to glacial hazards. Progress in Physical Geography, 29, 475-505.

R Core Team. 2015. R: A Language and Environment for Statistical Computing. Vienna, Austria: R Foundation for Statistical Computing.

Racoviteanu, A., Y. Arnaud, M. Williams \& J. Ordonez. 2008. Decadal changes in glacier parameters in the Cordillera Blanca, Peru, derived from remote sensing. Journal of Glaciology, 54, 499-510.

Racoviteanu, A., M. Williams \& R. Barry. 2008. Optical Remote Sensing of Glacier Characteristics: A Review with Focus on the Himalaya. Sensors (Basel, Switzerland), 8, 3355-3383.

Racoviteanu, A. \& M. W. Williams. 2012. Decision Tree and Texture Analysis for Mapping Debris-Covered Glaciers in the Kangchenjunga Area, Eastern Himalaya. Remote Sensing, 4, 3078.

Racoviteanu, A. E., W. F. Manley, Y. Arnaud \& M. W. Williams. 2007. Evaluating digital elevation models for glaciologic applications: An example from Nevado Coropuna, Peruvian Andes. Global and Planetary Change, 59, 110-125.

Ranzi, R., G. Grossi, L. Iacovelli \& S. Taschner. 2004. Use of multispectral ASTER images for mapping debris-covered glaciers within the GLIMS Project. In Geoscience and Remote Sensing Symposium, 2004. IGARSS'04. Proceedings. 2004 IEEE International, 1144-1147. IEEE. 
Raup, B., A. Kääb, J. S. Kargel, M. P. Bishop, G. Hamilton, E. Lee, F. Paul, F. Rau, D. Soltesz, S. J. S. Khalsa, M. Beedle \& C. Helm. 2007. Remote sensing and GIS technology in the Global Land Ice Measurements from Space (GLIMS) Project. Computers \& Geosciences, 33, 104-125.

Raup, B. \& S. J. S. Khalsa. 2010. GLIMS Analysis Tutorial. GLIMS.

Reynolds, J. M. 2000. On the formation of supraglacial lakes on debris-covered glaciers. IAHS publication, 153-164.

Saliola, A. 2014. Object-based image analysis for the delineation of canopy gaps and individual tree crowns using multi-source data: A case study in Haliburton Forest, Ontario. University of Toronto.

Shukla, A. \& I. Ali. 2016. A hierarchical knowledge-based classification for glacier terrain mapping: a case study from Kolahoi Glacier, Kashmir Himalaya. Annals of Glaciology, 57, 10.

Shukla, A., M. Arora \& R. Gupta. 2010. Synergistic approach for mapping debriscovered glaciers using optical-thermal remote sensing data with inputs from geomorphometric parameters. Remote Sensing of Environment, 114, 1378-1387.

Shukla, A., R. P. Gupta \& M. K. Arora. 2010. Delineation of debris-covered glacier boundaries using optical and thermal remote sensing data. Remote Sensing Letters, 1, 11-17.

Sidjak, R. W. 1999. Glacier mapping of the Illecillewaet icefield, British Columbia, Canada, using Landsat TM and digital elevation data. International Journal of Remote Sensing, 20, 273-284.

Silverio, W. \& J. M. Jaquet. 2005. Glacial cover mapping (1987-1996) of the Cordillera Blanca (Peru) using satellite imagery. Remote Sensing of Environment, 95, 342350 .

Stokes, C. R., V. Popovnin, A. Aleynikov, S. D. Gurney \& M. Shahgedanova. 2007. Recent glacier retreat in the Caucasus Mountains, Russia, and associated increase in supraglacial debris cover and supra-/proglacial lake development. Annals of Glaciology, 46, 195-203. 
Story, M. \& R. Congalton. 1986. Accuracy assessment: a user's perspective. Photogrammetric engineering and remote sensing, 52, 397-399.

Taschner, S. \& R. Ranzi. 2002. Comparing the opportunities of Landsat-TM and Aster data for monitoring a debris covered glacier in the Italian Alps within the GLIMS project. In Geoscience and Remote Sensing Symposium, 2002. IGARSS'02. 2002 IEEE International, 1044-1046. IEEE.

Thompson, L. G., E. Mosley-Thompson, M. E. Davis, P. N. Lin, K. A. Henderson, J. Cole-Dai, J. F. Bolzan \& K. B. Liu. 1995. Late glacial stage and Holocene tropical ice core records from Huascaran, Peru. Science, 269, 46-50.

Trimble. 2012. eCognition Developer v8.7 User Guide.

Tweed, F. S. \& J. L. Carrivick. 2015. Deglaciation and proglacial lakes. Geology Today, 31, 96-102.

USGS. 2013. Using the USGS Landsat 8 Product. United State Geological Survey.

USGS. 2015. Landsat 8 Data User's Handbook. Souix Falls, SD: United States Geological Survey.

van Exel, M. 2010. Bing Aerial Imagery Analyzer for OpenStreetMap.

Vaughan, D. G., J. C. Comiso, I. Allison, J. Carrasco, G. Kaser, R. Kwok, P. Mote, T. Murray, F. Paul, J. Ren, E. Rignot, O. Solomina, K. Steffen \& T. Zhang. 2013. Observations: Cryosphere. In Climate Change 2013: The Physical Science Basis. Contribution of Working Group I to the Fifth Assessment Report of the Intergovernmental Panel on Climate Change, eds. T. F. Stocker, D. Qin, G.-K. Plattner, M. Tignor, S. K. Allen, J. Boschung, A. Nauels, Y. Xia, V. Bex \& P. M. Midgley, 317-382. Cambridge, United Kingdom and New York, NY, USA: Cambridge University Press.

Veettil, B. K. 2012. A Remote sensing approach for monitoring debris-covered glaciers in the high altitude Karakoram Himalayas. International Journal of Geomatics and Geosciences, 2, 833-841.

Wagnon, P., P. Ribstein, G. Kaser \& P. Berton. 1999. Energy balance and runoff seasonality of a Bolivian glacier. Global and Planetary Change, 22, 49-58. 
Warren, S. G. 1982. Optical properties of snow. Reviews of Geophysics, 20, 67-89.

WGMS. 2015. latest glacier mass balance data. ed. W. G. M. Service. Zurich: QWorld Glacier Monitoring Service.

Williams, R. S., Jr \& J. G. Ferrigno. 2012. State of the Earth's cryosphere at the beginning of the 21 st century-Glaciers, global snow cover, floating ice, and permafrost and periglacial environments. In U.S. Geological Survey Professional Paper, ed. U. S. G. Survey. U.S. Geological Survey

Zemp, M., M. Hoelzle \& W. Haeberli. 2009. Six decades of glacier mass-balance observations: a review of the worldwide monitoring network. Annals of Glaciology, 50, 101-111. 


\section{APPENDIX A: R Programming Code for Tree-Based Classifiers}

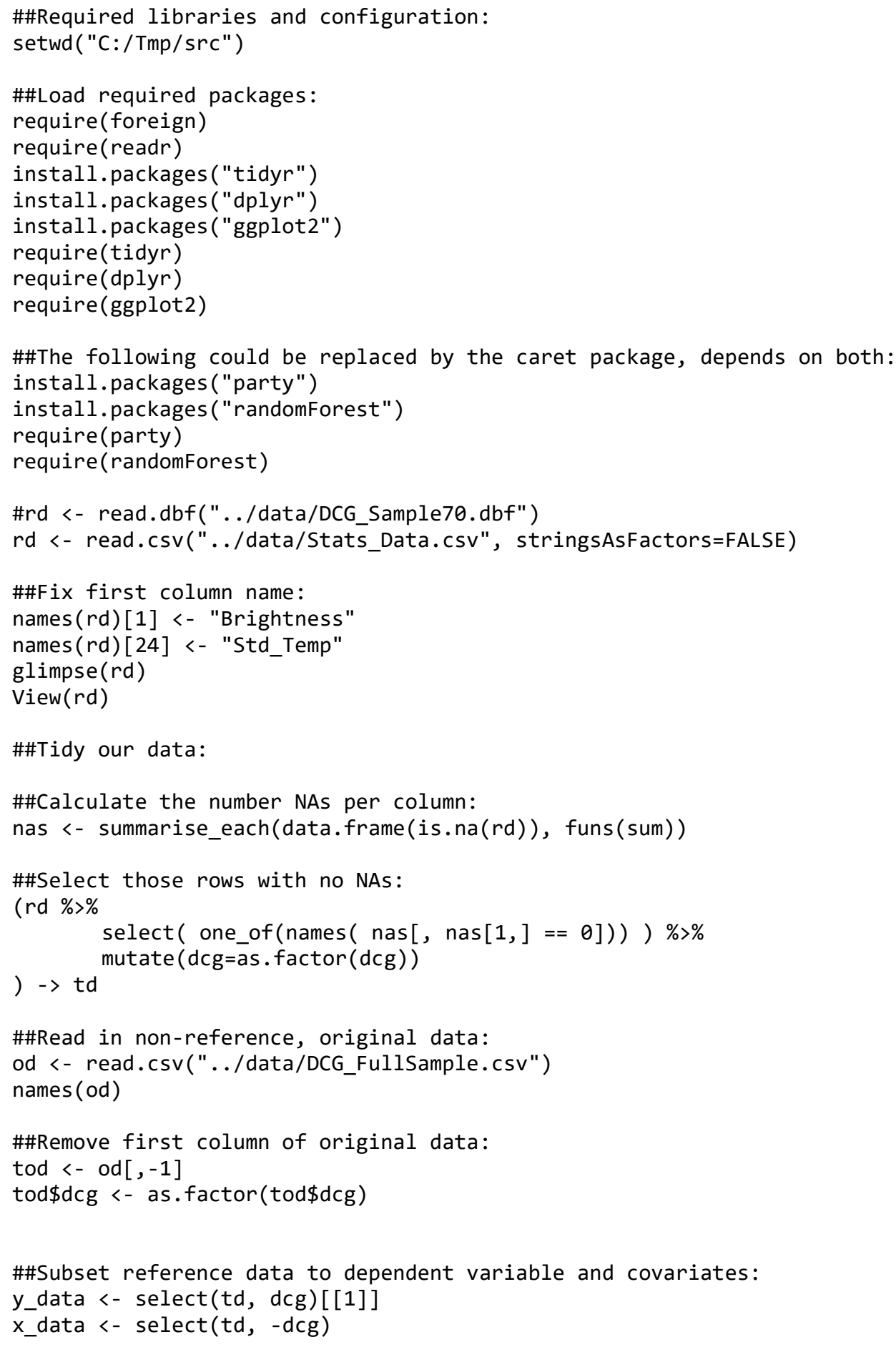




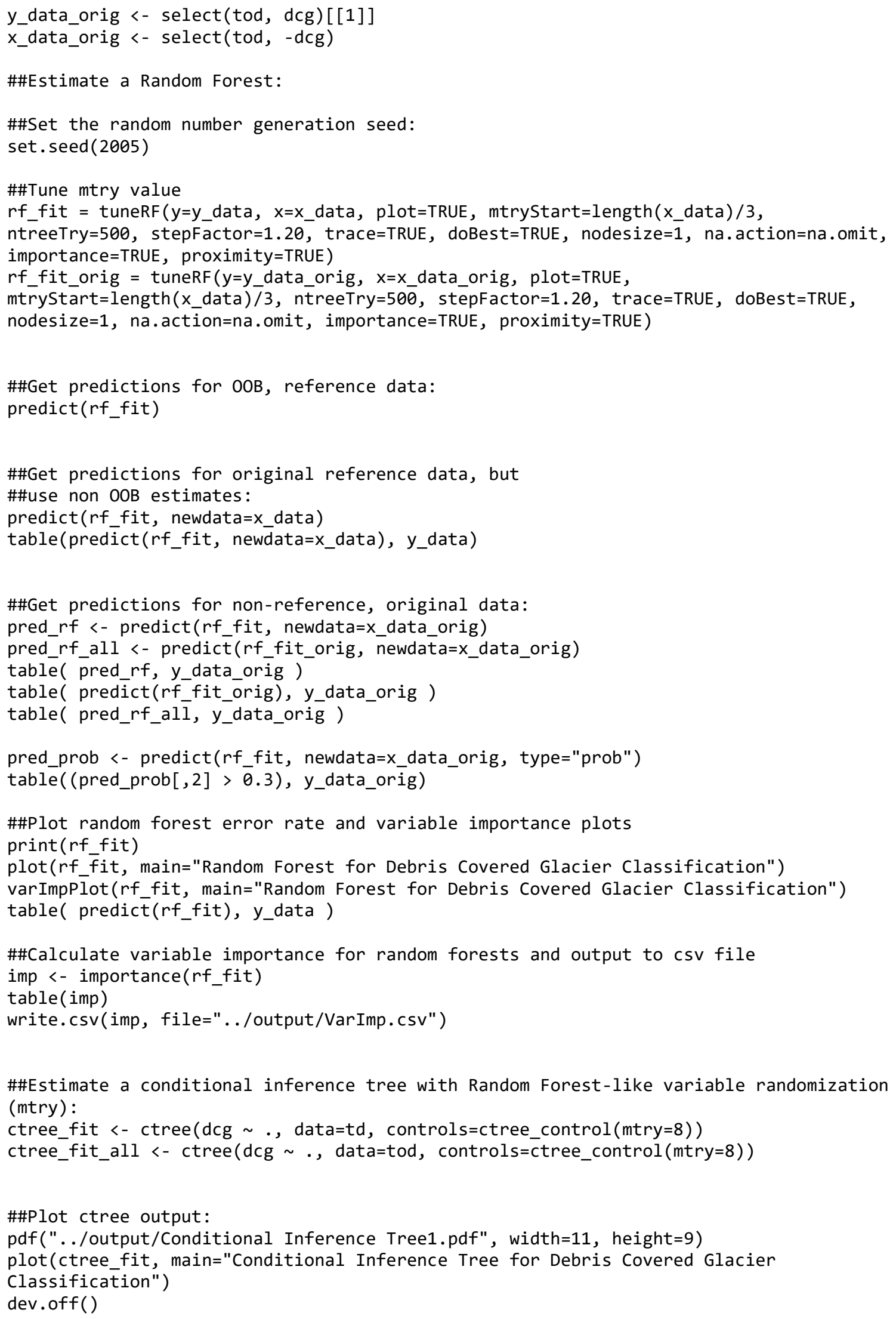




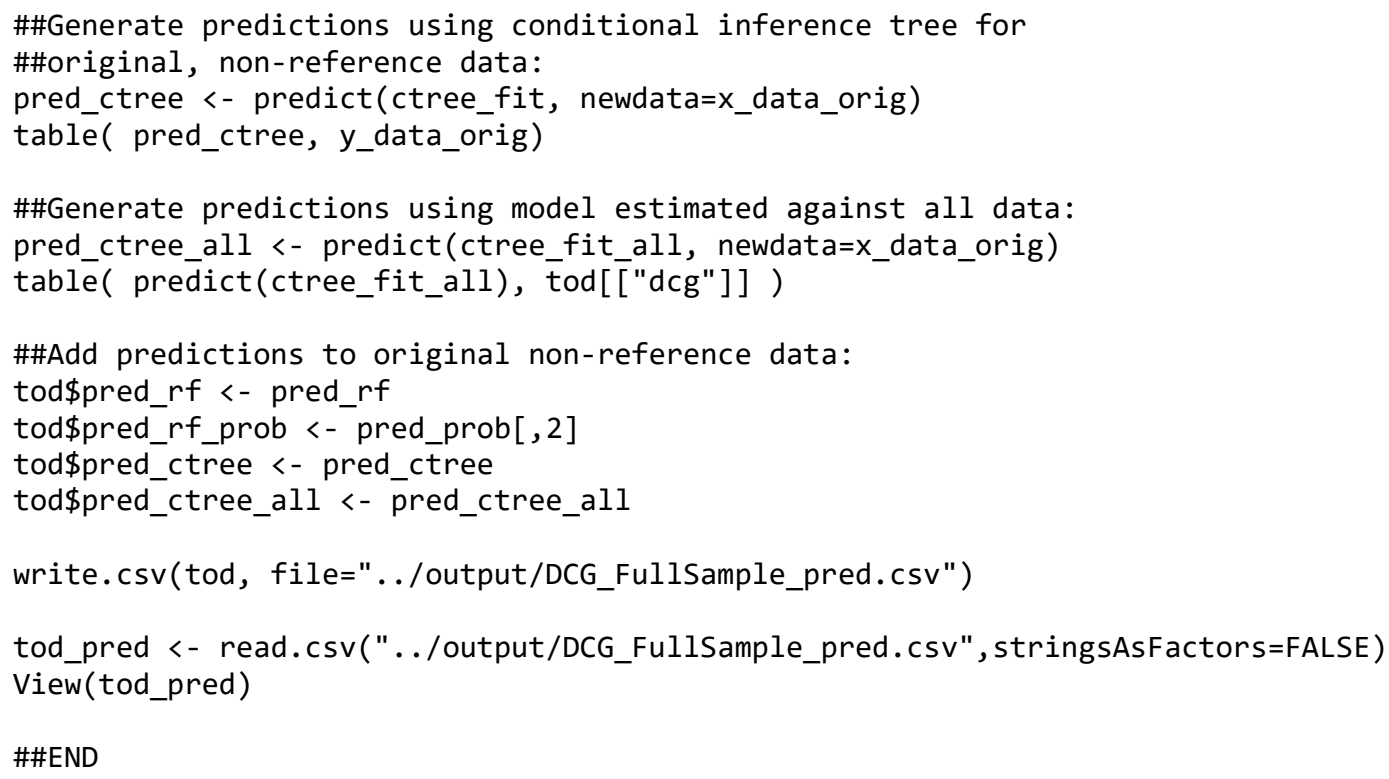




\section{CURRICULUM VITAE}

NAME:

ADDRESS

DOB:

EDUCATION

\& TRAINING:

AWARDS:

PROFESSIONAL SOCIETIES:
Donald Joseph Biddle

Department of Geography and Geosciences

220 Lutz Hall

University of Louisville

Louisville, KY 40292

Louisville, Kentucky - January 15, 1982

B.S., Applied Geography

University of Louisville

2002-2005

GISP Certification

GIS Certification Institute

2014

Community Engagement Award

University of Louisville

2010

Undergraduate Fellow

National Science Foundation

Groundwork Education in Math \& Science (GEMS) program 2004-2005

Eagle Scout

Boy Scouts of America

2000
Association of American Geographers, Kentucky Association of Mapping Professionals 
NATIONAL MEETING PRESENTATIONS:

TEACHING

EXPERIENCE:
Biddle, D.J., Gaughan, A.E., Stevens, F.R. 2015. Mapping Debris-Covered Glaciers in the Cordillera Blanca, Peru: An Object-based Image Analysis Approach. Interactive Poster presented at the 2014 Annual Meeting of the Assoc. of American Geographers

Geography 559: Advanced Geographic Information Systems, 2010 - 2015, University of Louisville

Geoscience 200: The Global Environment (online course), 2010-2015, University of Louisville 